Proposal Control Number U9808012

DOE Award Number DE-FG26-98FT40359

FINAL REPORT

Reporting Period 6/19/98-3/31/99

\title{
High Efficiency, Quasi-Instantaneous Steam Expansion Device Utilizing Fossil or Nuclear Fuel as the Heat Source
}

Thermal-Hydraulic Analysis

Prepared by Claudio Filippone, Ph.D.

Department of Materials and Nuclear Engineering University of Maryland

Prepared for

U.S. Department of Energy

Federal Energy Technology Center

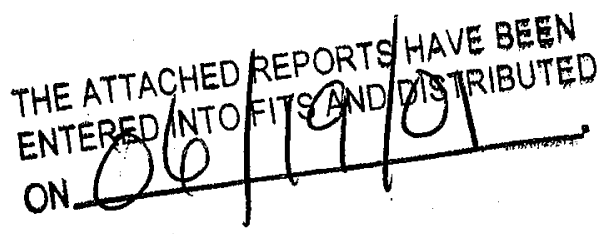




\begin{abstract}
Thermal-hydraulic analysis of a specially designed steam expansion device (heat cavity) was performed to prove the feasibility of steam expansions at elevated rates for power generation with higher efficiency. The steam expansion process inside the heat cavity greatly depends on the "gap" within which the steam expands and accelerates.

This system can be seen as a miniaturized boiler integrated inside the expander where steam (or the proper fluid) is generated almost instantaneously prior to its expansion in the workproducing unit. Relatively cold water is pulsed inside the heat cavity, where the heat transferred causes the water to flash to steam, thereby increasing its specific volume by a large factor. The gap inside the heat cavity forms a special nozzle-shaped system in which the fluid expands rapidly, accelerating toward the system outlet. The expansion phenomenon is the cause of everincreasing fluid speed inside the cavity system, eliminating the need for moving parts (pumps, valves, etc.). In fact, the subsequent velocity induced by the sudden fluid expansion causes turbulent conditions, forcing accelerating Reynolds and Nusselt numbers which, in turn, increase the convective heat transfer coefficient. When the combustion of fossil fuels constitutes the heat source, the heat cavity concept can be applied directly inside the stator of conventional turbines, thereby greatly increasing the overall system efficiency.
\end{abstract}

Proposal No. U9808012 
Proposal Control Number U9808012

DOE Award Number DE-FG26-98FT40359

FINAL REPORT

Reporting Period 6/19/98-3/31/99

\section{High Efficiency, Quasi-Instantaneous Steam Expansion Device Utilizing Fossil or Nuclear Fuel as the Heat Source}

Thermal-Hydraulic Analysis

Manuscript Completed: June 1999

Prepared by

Claudio Filippone, Ph.D.

Phone: (301) 403-4487

Fax: (301) 403-4459

CD-ROM File Name: 40359R01

Department of Aerospace Engineering

University of Maryland

College Park, MD 20742

Prepared for

U.S. Department of Energy

Federal Energy Technology Center

AAD Document Control, MS 921-143

P.O. Box 10940

Pittsburgh, PA 15236-0940 


\section{TABLE OF CONTENTS}

$\begin{array}{ll}\text { ABSTRACT } & \text { i }\end{array}$

TABLE OF CONTENTS ii

$\begin{array}{ll}\text { EXECUTIVE SUMMARY } & 1\end{array}$

CHAPTER 1

$\begin{array}{ll}1.1 \text { INTRODUCTION } & 3\end{array}$

1.1 BACKGROUND : $\quad 3$

$\begin{array}{ll}1.3 \text { PRIOR ART } & 3\end{array}$

1.4 CYLINDRICAL HEAT CAVITY MODEL $\quad$. 4

$\begin{array}{ll}1.5 \text { CYLINDRICAL HEAT CAVITY ANALOG } & 7\end{array}$

1.5 CYLINDRICAL HEAT CAVITY EXPERIMENTAL SETUP $\quad 8$

$\begin{array}{ll}1.5 \text { CYLINDRICAL HEAT CAVITY RESULTS } & 8\end{array}$

1.5 CONCLUSIONS OF THE CYLINDRICAL HEAT CAVITY 11 EXPERIMENTATION

CHAPTER 2

2.1 RECTANGULAR HEAT CAVITY 8-9kW POWER 12

2.1 RECTANGULAR HEAT CAVITY THEORETICAL MODEL 12

2.1 RECTANGULAR HEAT CAVITY ACTUAL MODEL 14

2.1 RECTANGULAR HEAT CAVITY PROTOTYPE SPECIFICATIONS 15

2.1 EXPERIMENTAL SETUP 16

$\begin{array}{lll}2.1 & \text { EXPERIMENTAL RESULTS } & 17\end{array}$

CHAPTER 3

3.1 MATHEMATICAL CORRELATION 24

3.1 DETERMINATION OF THE П TERMS 25

3.1 CONCLUSIONS AND RECOMMENDATIONS $\quad 28$ 


\section{APPENDIXES}

APPENDIX A (Note: Different Page Numbering From Different Technical Papers)

APPENDIX B (Note: Different Page Numbering From Different Technical Papers)

APPENDIX C (Note: Different Page Numbering From Different Technical Papers) 


\section{EXECUTIVE SUMMARY}

This technical paper reports the results of the first two of five design phases of a proposal entitled "Quasi-Instantaneous Steam Expansion Device Utilizing Fossil or Nuclear Fuels as the Heat Source."

The critical factors determining the high efficiency of heat cavity systems able to produce instantaneous steam with the desired thermodynamic state are strongly dependent on the geometry of the internal parts of the heat cavity. In particular, the dimensions of the annulus formed by two concentric cylinders, or the gap between flat surfaces, in conjunction with the heat rate and the mass flow rate of fluid have to be fine-tuned with one another to provide a highly efficient energy conversion system. The working models used for the experimentation utilized a 1,300 psi pulsed positive displacement pump, and a series of high-pressure injectors for the subcooled water injection inside the annulus/gap of the heat cavity. Two basic prototypes were assembled to prove the feasibility of extremely rapid steam expansions as a more efficient way to utilize the heat from the energy source (i.e. combustion of fossil fuels, or fissioning of nuclear fuel). One small-scale prototype was assembled with a cavity formed by two concentric cylinders. The outer diameter of the inner cylinder was only 1 inch and the annulus formed had a maximum clearance of $0.25 \mathrm{~mm}$. A large-scale and more powerful heat cavity system, with rectangular geometry, was also assembled and tested. In both models of heat cavities, electric heaters were utilized to simulate the heat cavity temperature gradient otherwise normally reached by combustion of fossil fuels or the fission reaction of nuclear fuels. The maximum power dissipated inside the cylindrical heat cavity was approximately $1.2 \mathrm{~kW}$, while the power dissipated in the rectangular heat cavity was approximately $9 \mathrm{~kW}$ (comparable with small-scale power generating systems). In both cases, quasi-instantaneous superheated steam was obtained at the outlet of the heat cavities with the pressure and mass flow rates desired, thereby demonstrating the feasibility of superheated steam production with higher efficiencies than that obtained by utilizing conventional steam generating systems.

The experimental results of this preliminary investigation were utilized to establish the most optimized physical dimensions of the heat cavity so that it can be scaled and integrated inside the stator structure of conventional turbines. In other words, the mathematical correlation derived from this study can be utilized to design larger models, or adapt the heat cavity concepts to conventional large-scale system with a significant impact on the power system's energy conversion efficiency and economics.

This preliminary investigation shows that quasi-instantaneous steam expansions can be generated and controlled inside extremely compact heat cavities in which cold water (or the proper fluid) is injected at the heat cavity inlets and superheated steam (or vapor) is obtained at their outlet instantaneously. The immediate effect of the integration of these concepts inside the body structure of conventional steam turbines is that of dramatically decrease the entropy generation (or energy availability destruction) normally accompanying conventional boiler/burners structures and associated piping and steam admission valve systems. The integration of heat cavities with conventional power turbines is extremely simple and inexpensive since the heat cavity device can be coupled and sealed to the connecting flange of the steam admission port of conventional turbine/s. Thanks to the results of this investigation, it 
is now possible to assemble a larger scale model of the heat cavity in which the heat source is the actual hot gases produced by combustion of fossil fuels. The integration of the proposed design inside conventional power generating systems can significantly improve their efficiency, and automatically reduce the rate of environmental degradation. 


\subsection{Introduction}

The first two phases of the quasi-instantaneous steam expansion experiment were dedicated to proving the feasibility of the heat cavity concept and to the determination of a mathematical correlation. A series of correlations will allow the expansion phenomenon to be scaled to large conventional systems, and prove that controlled steam explosion can represent a more efficient way to convert energy from the heat source to the power generating unit. The proposal of the "quasi instantaneous steam expansion device utilizing fossil or nuclear fuel as the heat source" includes 5 phases. This preliminary study reports the results of the research conducted for Phases 1 and 2 of the proposal. These initial two phases consisted of six months dedicated to the designing and assembling of prototypes for the preliminary testing:

\section{- Phase 1: Assembly of a Heat Cavity Model}

\section{- Phase 2: Scaling of the Expansion Phenomenon}

\subsection{Background}

A first set of successful experimental data regarding experimentation conducted from 1993 to 1996 was obtained by analyzing a relatively small working model with a total volume of only $170 \mathrm{cc}$. Further experiments conducted in 1996 proved that the fluid (steam) can be expanded at extremely high rates, thereby making the utilization of fast expansion phenomena possible directly inside a conventional expander with no need for accumulation of superheated steam in a boiler, and no need for steam admission valves and piping. In fact, by integrating the heat cavity system into a standard turbine/expander, the conventional boiler/valves/piping structure normally utilized are eliminated. In this manner, relatively cold water circulates inside the whole power system except inside the heat cavity/ies, where it is rapidly converted into steam at the desired pressure and temperature prior to its expansion inside the turbine/expander.

\subsection{Prior Art}

The experiments conducted from 1993 to 1996 showed that only $1.9210^{-4} \mathrm{Kg}$ of water was needed to generate work by "instantaneously" expanding the subsequent steam inside a reciprocating expander whose total volume was only $170 \mathrm{cc}$. Since then, further research has been conducted in an effort to increase the dimensions of the heat cavities to determine the key parameters governing the "explosive" nature of the expansion phenomenon inside the heat cavity. The main objective of the heat cavity concept is increasing the energy conversion efficiency by eliminating most of the thermodynamic irreversibility sources normally present in conventional power systems. In fact, as explained in detail in Chapter 2.1a and 2.1b of the paper entitled: "Toward the Nuclear Powered Steam Expansion Engine," by C. Filippone (Appendix A), by comparing the irreversibility rate and/or the flow availability destruction rate generated in the steam admission valve to the irreversibility originated in the turbine alone, the resulting ratio of the two irreversibilities is about $73 \%$. Therefore, by considering such a large value of 
availability destruction (or irreversibility production) due to the turbine admission valve alone, it is clear that there is room for improvement.

Additional studies conducted since June 1998 have shown that larger heat cavity systems allow the effects of the rapid steam expansion to be scaled as desired when the mass flow rate of the working fluid changes from a few milligrams to grams and kilograms (as is necessary for large conventional energy producing units). Therefore, the application of heat cavity systems is a feasible and inexpensive alternative to improve the efficiency of conventional power systems, and automatically decreasing environmental degradation by discharging less heat in the environment.

To achieve Phase 1, a cylindrical heat cavity system was assembled and the experimental results were utilized to design and assemble a much larger heat cavity system. The heat cavity prototypes were equipped with fast data acquisition instrumentation to provide data needed to generate the mathematical correlation between the thermodynamic parameters involved in the steam expansion process occurring inside the heat cavity and the physical dimensions of the heat cavity itself. The empirical correlation obtained in this first phase was then further refined and optimized by assembling an even larger heat cavity, ready to be coupled with a work producing unit (i.e. expander/turbine).

Phase 2 was dedicated to further optimizing the heat cavity model designed and assembled in Phase 1. A much larger heat cavity was formed by assembling a rectangular, fixedgap heat cavity system. The analysis of the data attained from the combination of the cylindrical and the rectangular heat cavities provided a set of tables which can be utilized to generate specific mathematical correlations. The correlations provide an empirical tool to predict the behavior of the heat cavity outlet fluid characteristics when the overall dimensions/surfaces of the heat cavity itself are modified, especially when the mass flow rate at the heat cavity inlet is increased or decreased.

\subsection{Cylindrical Heat Cavity Model}

The cylindrical heat cavity model was initially assembled by winding a Nickel-Chrome (Ni-Cr) wire (1) on a ceramic tube (2) provided by CeramTek, Inc. As shown in Fig. 1.1, the Ni$\mathrm{Cr}$ wire is wound on a ceramic support (2), forming a compact coil (4). This coil was then inserted inside a cladding tube (3), which was machined to allow the insertion of additional cladding material. The additional cladding material had the purpose to provide means to vary the dimensions of the annulus formed between the cladding tube and the surrounding inner walls of tube. The compact coil formed by wire, and ceramic support was then filled with ceramic cement and sealed on one end. 


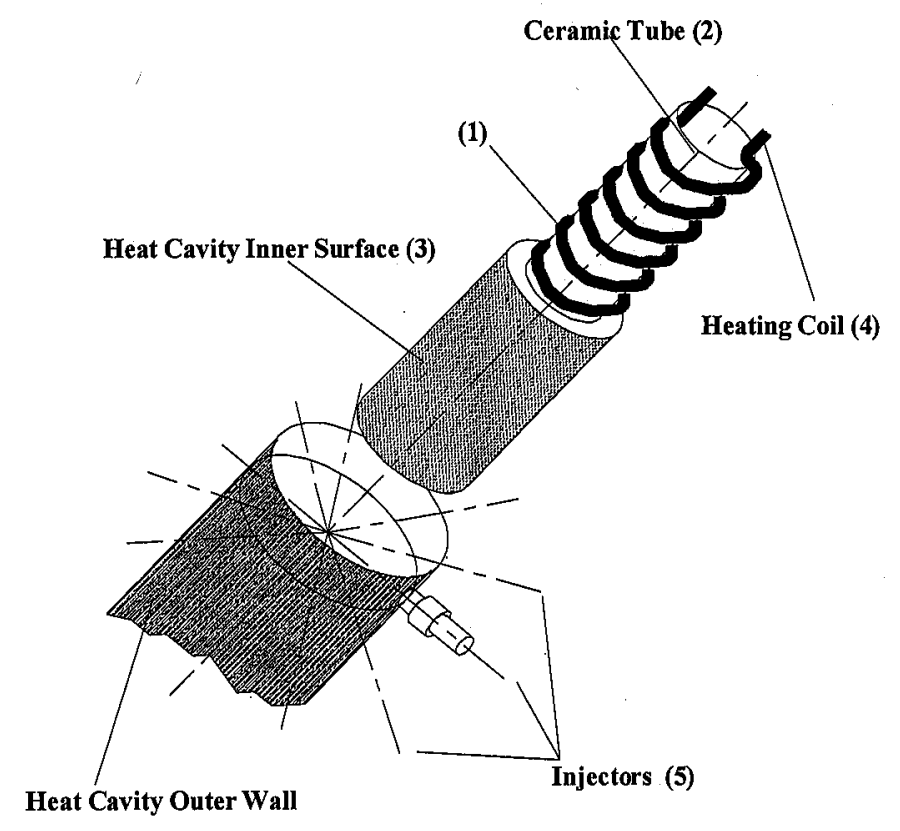

Fig. 1.1: Cylindrical Heat Cavity Model Ceramic Support

High pressure (1,200-1,300 psi) subcooled liquid water was pulsed inside the system through a high-pressure positive displacement pump and the injector (5). Since the ceramic support was donated by CeramTek, Inc., this model was extremely inexpensive and practical; unfortunately, it was not as functional as expected. As soon as this first heat cavity was assembled and tested, the ceramic compound started to crack, thereby failing in its purpose of mechanically supporting the $\mathrm{Ni}-\mathrm{Cr}$ wire. The damage on the ceramic compound was mainly caused by the high rate of temperature changes and gradients between the $\mathrm{Ni}-\mathrm{Cr}$ wire and the unavoidable air gaps formed during the manufacturing processes which required vacuum chambers not available at the Department of Materials and Nuclear Engineering. Furthermore, the dimension of the gap clearance between the concentric cylinders was such that the temperature gradient between the steam forming inside the annulus and the surface temperature of the heater was too large, thereby inducing mechanical contractions/expansions. The manufacturing of a custom-made high temperature ceramic support with more appropriate thermal-physical properties (particularly the expansion coefficient) for the heat cavity experiment was unaffordable under the given research budget and schedule. Therefore, another cylindrical heat cavity was designed by utilizing inexpensive components as shown in Fig. 1.2a, and Fig. 1.2b. In this case, a cylindrical heater (1) is inserted inside a hollow stainless steel tube. The heater (1) is locked and sealed inside the hollow tube by a plug (3). On the hollow tube, a high pressure injector ((4) in Fig. 1.2a, (5) in Fig. 1.2b) is inserted through the injector port. The outer radius of heater is kept 0.25 millimeter less than the inner radius of the hollow tube. 


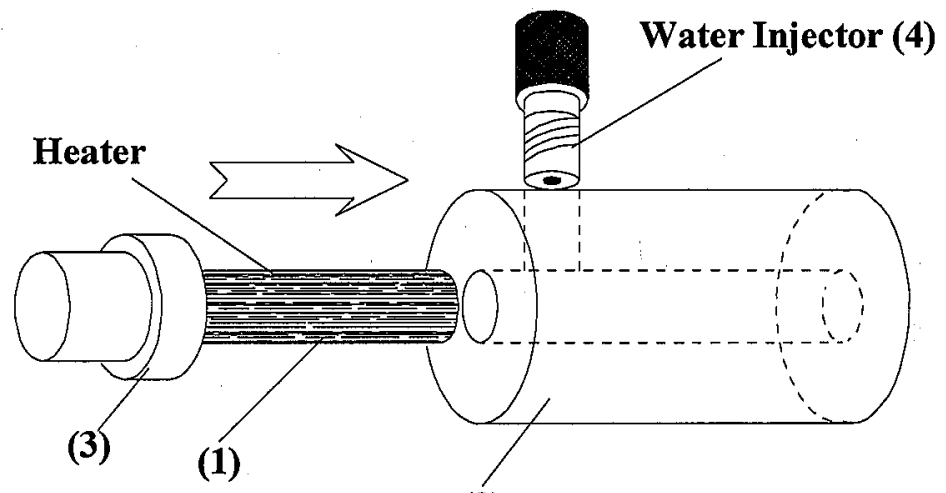

(2)

Fig. 1.2a: Cylindrical Heat Cavity Stainless Steel Support

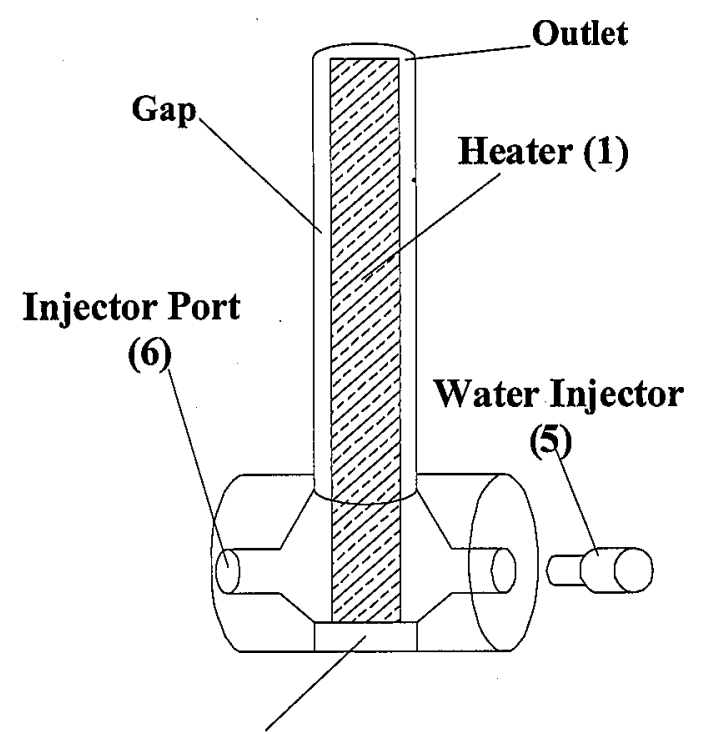

Electric Plug (3)

Fig. 1.2b: Cylindrical Heat Cavity Carbon Steel Support

The gap so formed is fixed and does not allow fine-tuning of the gap of the heat cavity. However, by regulating the mass flow rate of the water injected through injector (4) (or (5)), and the current across heater (1), it was possible to obtain a first set of data which were then utilized to optimize the design of a much larger heat cavity with rectangular geometry. A larger scale model of the cylindrical heat cavity is shown in Fig. 1.3. In this figure, the heat source is represented by the inner cylinder (1) which can receive heat from the combustion gases produced 
by burning fossil fuels as well as heat produced by the fissioning of nuclear fresh fuel, or decay heat from spent nuclear fuel.

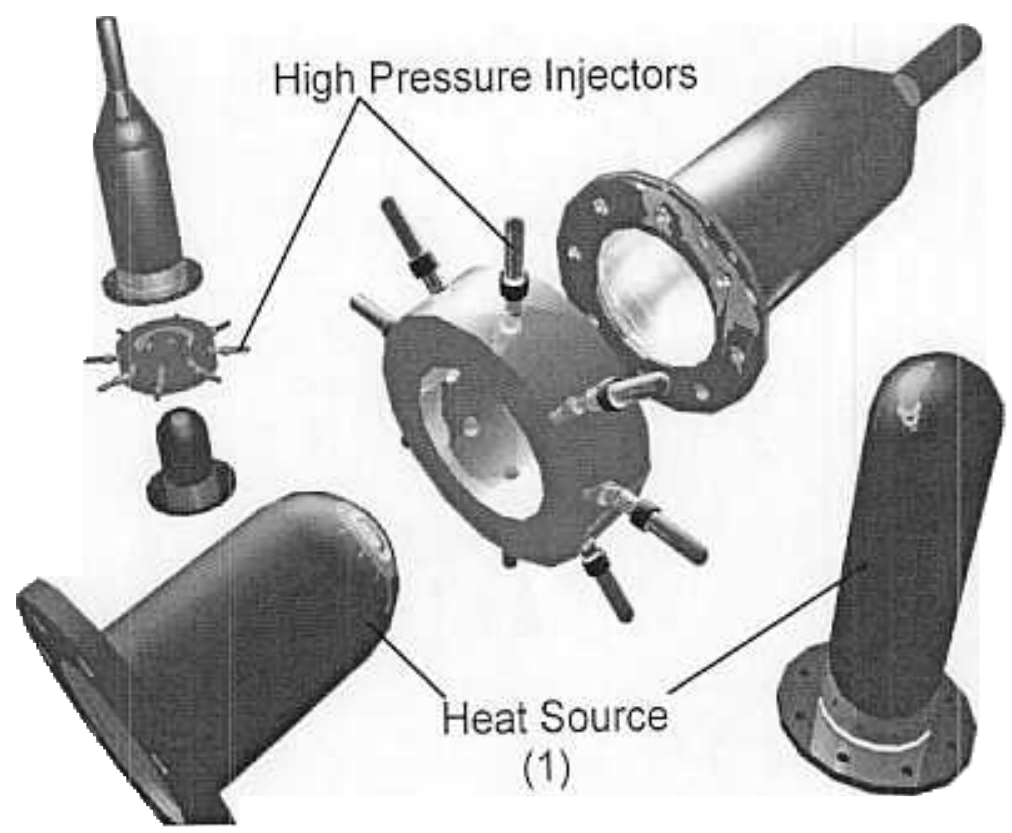

Fig. 1.3: Cylindrical Heat Cavity Utilizing Fossil Fuel Heat Source

\subsection{Cylindrical Heat Cavity Analog}

The prototype of the cylindrical heat cavity was assembled by inserting an electric heater 1 inch in diameter inside a stainless steel pipe. The gap formed between the surface of the heater and the inner wall of the stainless steel pipe was only $0.25 \mathrm{~mm}$. As it will be shown by the experimental results, despite this extremely narrow gap, the energy transferred inside the gap was not optimized. In fact, the results suggested that an even smaller gap was required. The stainless steel body of the cylindrical heat cavity was designed to withstand a maximum pressure of about 3,000 psi. However, for safety reasons, the working pressure during the experiment was made to not overcome 300 psi.

A series of thermocouples were placed at approximately $2.5 \mathrm{~cm}$ from one another, and a modified high pressure diesel fuel injector was utilized as a check valve for the injection of cold water inside the gap. Finally, a series of pressure gauges were placed at the outlet of the annulus formed by the heater and the stainless steel pipe. To improve safety, the mechanical supports for the thermocouples were welded to the external body of the cavity itself.

The prototype of the $1.2 \mathrm{~kW}$ cylindrical heat cavity is shown in Fig. 1.4. 


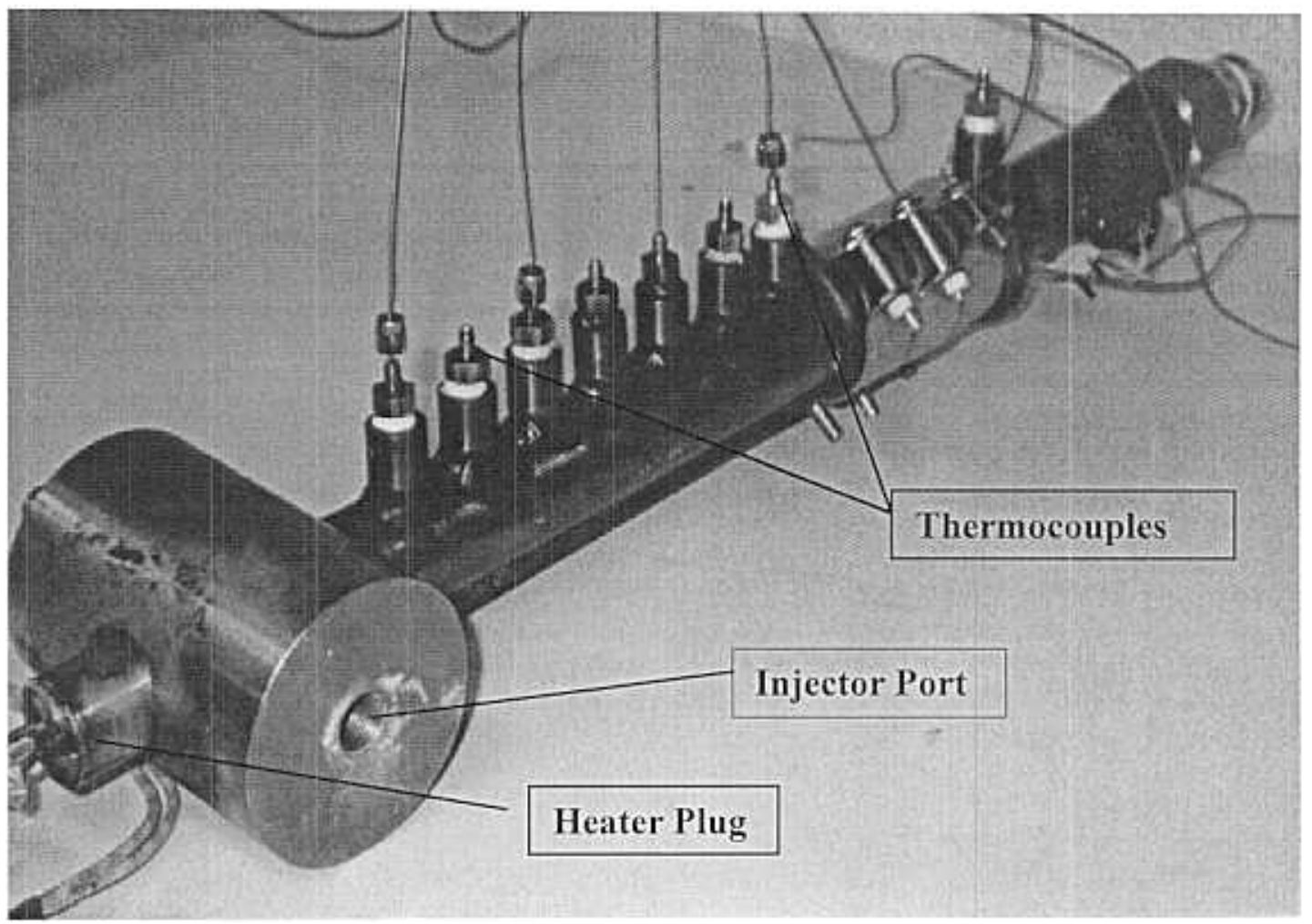

Fig. 1.4: Heat Cavity Analog

\subsection{Cylindrical Heat Cavity Experimental Setup}

After having had significant problems with the stabilization of the mass flow rate of water injected, the experimental set up for this first cylindrical heat cavity model was completed and the first set of data was obtained. The experimental results are plotted in Graph 1.1, and the experimental set-up consisted of:

- Power supply unit to control the current on the heater contained inside the cylindrical heat cavity (voltage range from 0 to 220 Volts)

- 1,300 psi electric positive displacement pump

- Two modified diesel injector (spring loaded with the spring constant calibrated to open at a pressure of 650-700 psi)

- Water tank

- Data acquisition system (16 Channels)

- Pressure gauges 0-300 psi

- K- type thermocouples

- Specially shaped outlet nozzle

- Discharge and safety valve system

- Stainless steel vessel surrounding the heater and forming a gap of $0.25 \mathrm{~mm}$ 


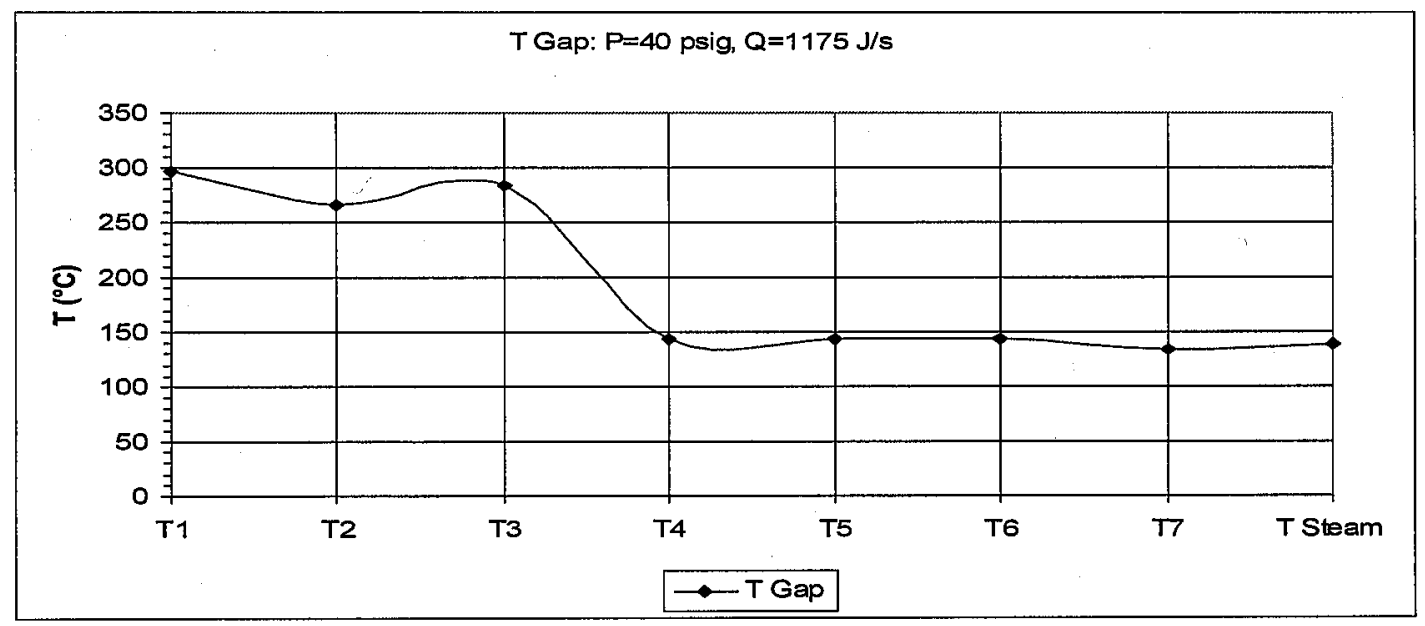

\section{Graph 1.1: Cylindrical Heat Cavity}

The temperature on the heater surfaces was kept at a maximum of $350{ }^{\circ} \mathrm{C}$, and the thermocouples were spaced 1 inch from one another (Fig. 1.2). Overall, $7 \mathrm{k}$-type thermocouples (T1-T7) were positioned at $0.1 \mathrm{~mm}$ from the surface of the heater (measuring steam temperature), while $\mathrm{T}$ Steam corresponded to a thermocouple positioned in a region of the cavity away from the annulus, so as to measure the temperature of the steam accumulating right at the outlet of the annulus. T exit reported in Table 1.1 corresponds to a thermocouple positioned 1 inch prior to the exit nozzle of the heat cavity. Since the heat cavity was not thermally insulated the steam temperature decrease from $\mathrm{T}$ Steam $=138.54^{\circ} \mathrm{C}$ to $\mathrm{T}$ exit $=123.7^{\circ} \mathrm{C}$ allows the computation of the heat losses from the external surfaces of the heat cavity.

\subsection{Cylindrical Heat Cavity Results}

Once the heat cavity was powered and water was injected at approximately $1,250 \mathrm{psi}$ with an average mass flow rate $\mathrm{dm} / \mathrm{dt}=0.19 \mathrm{1} / \mathrm{m}$, the pressure developed inside the gap started to dangerously fluctuate due to instability in the mass flow rate. Very long data acquisition times were necessary to average the mass flow rate and the gap temperature variations. However, the instability caused by the positive displacement pump was so severe that a variation of $30 \%$ of the mass of water injected induced a variation of more than $200 \%$ of the pressure developed inside the annulus. In two instances a pressure fitting, holding a k-type thermocouple, and a pressure gauge literally exploded. In one respect this was positive since we were investigating the feasibility of generating steam explosions; however, it was clear that a safer, more stable and controllable system was necessary. The production of steam inside the heat cavity was instantaneous as expected and could be maintained with thermodynamic properties at steady state (when the pump was stable) with a water mass flow rate of 190 milliliter per minute. The average pressure reached inside this prototype of heat cavity was about 40 psi with maximum pressure peaks of $120 \mathrm{psi}$. The speed of the steam exiting from the outlet nozzle was approximately $119 \mathrm{~m} / \mathrm{s}$. The numerical results of this experiment are shown in Table 1.1. 


\begin{tabular}{|c|c|r|}
\hline T1 & $\left({ }^{\circ} \mathrm{C}\right)$ & 296.85 \\
\hline T2 & $\left({ }^{\circ} \mathrm{C}\right)$ & 265.89 \\
\hline T3 & $\left({ }^{\circ} \mathrm{C}\right)$ & 284.54 \\
\hline T4 & $\left({ }^{\circ} \mathrm{C}\right)$ & 144.26 \\
\hline T5 & $\left({ }^{\circ} \mathrm{C}\right)$ & 144.1 \\
\hline T6 & $\left({ }^{\circ} \mathrm{C}\right)$ & 143.85 \\
\hline T7 & $\left({ }^{\circ} \mathrm{C}\right)$ & 134.27 \\
\hline T Steam & $\left({ }^{\circ} \mathrm{C}\right)$ & 138.54 \\
\hline T exit & $\left.{ }^{\circ} \mathrm{C}\right)$ & 123.69 \\
\hline P & $(\mathrm{w})$ & 1175.44 \\
\hline
\end{tabular}

Table 1.1: Cylindrical Heat Cavity

This first set of experiments was designed to optimize the heat cavity gap. The cylindrical shape of this prototype did not allow easy modification of the gap between the heater surface and the surrounding walls. For these reasons, the effect of gap or mass flow rate variations were later investigated with a different experimental set-up by utilizing the rectangular heat cavity described in detail in Chapter 2. As shown in Graph 1.1, the temperature of the steam exiting the heat cavity is about $138^{\circ} \mathrm{C}$, while the temperature of the heater at the location where the cold water injection occurs is about $300^{\circ} \mathrm{C}$ (the temperature of the water injected is $28^{\circ} \mathrm{C}$ ). In this experiment, steam reaches a steady thermodynamic state after only 3 inches of travel inside the heat cavity. Therefore, the speed of the expanding steam inside the heat cavity reaches steady state conditions fairly quickly (as indicated by the temperature reading T4). The large temperature gradient at the inlet of the heat cavity indicates that water flashes to steam immediately, but escapes that region of the heat cavity without absorbing all of the available heat. Therefore, this first set of results indicates that a smaller annulus is required. In fact, the temperature gradient should behave quite the opposite of what is shown in Graph 1.1. According to heat transfer and thermodynamic calculations, the temperature of the steam expanding inside the heat cavity should increase while traveling toward the outlet of the annulus, and eventually reach an equilibrium temperature. In Graph 1.1, the temperature in the gap is too high at the inlet, between $\mathrm{T} 1$ and $\mathrm{T} 3$, and it reaches equilibrium too early (T5, only 5 inches from the inlet).

In general, the problems encountered with this experiment were mainly due to the pulsed nature of the positive displacement pressure pump. This inexpensive pump is a modified pressure washer pump which becomes easily unstable whenever micro air bubbles form at its suction and inside its valve system. To compensate for the pump instability long periods of data acquisition were utilized so as to minimize the error. Another limitation was imposed by the limited power dissipated by the heater (only $1.2 \mathrm{~kW}$ max). However, the results of this first experiment showed that steam can be produced instantaneously from cold water on a steady state basis at a designed rate as predicted by the thermodynamic computation. Therefore, the theoretical concept of producing steam right in front of the blades of a steam turbine, without accumulating it in heat-losing and entropy-generating tanks and pipes is now a step closer to a real system with several applications. 


\subsection{Conclusions of the Cylindrical Heat Cavity Experimentation}

This experiment showed that a minimum variation in the sub cooled liquid water mass flow rate at the cavity inlet causes severe variations in the pressure inside the annulus. If the pressure inside the heat cavity varies so quickly the spring loaded injector valve starts to oscillate and the mass flow rate becomes even more unstable. The cylindrically shaped heat cavity has been designed to withstand pressure variations 10 times larger than those predicted in the thermodynamic analysis, therefore there was no danger during the experiment. However, these phenomena showed that a reinforced structure for the rectangular shaped heat cavity was necessary. In fact, the mechanical model of the rectangular heat cavity designed in 1998 would have been easily destroyed by the pressure variations encountered in the cylindrical heat cavity. For these reasons, the pressure seals and thickness of the rectangular heat cavity components have been redesigned and reinforced.

To summarize, the first experiment successfully showed that about 1,100 watts could generate a steady state mass flow of $0.19 \mathrm{l} / \mathrm{m}$ of steam at $\mathrm{P}=40-45 \mathrm{psi}$. The heat losses from the system (cooled by natural convection with air on the outside, where the convective heat transfer coefficient was assumed to be $25 \mathrm{~W} / \mathrm{m}^{2} \mathrm{~K}$ ), indicated that only 700 watts would be sufficient to provide steam with the above mass flow rate and pressure. Thanks to the results of this first prototype, a more sophisticated heat cavity could be designed, and a more in-depth analysis on the key parameters governing the instantaneous expansion phenomena was possible on a larger heat cavity system as it is explained in the following chapter. 


\subsection{Rectangular Heat Cavity 8-9 kW Power}

The experiments conducted on the small-scale cylindrical heat cavity provided the information needed for the design of a safer, more controllable, and more powerful heat cavity system. Significant efforts were dedicated to the correction of the pressure fluctuations induced by the positive displacement pump. In this second set of experiments, the mass flow rate was successfully stabilized by inserting a pressurized tank in the high pressure circuit prior to the water injectors. The high pressure tank was first pressurized with air up to a pressure of $250 \mathrm{psi}$. Water was then pumped at 1,300 psi inside the tank, thereby trapping the air at the top. In this way the pressure pulsation provoked by the positive displacement pump was dampened by the "cushion" of air inserted in the hydraulic circuit. The gap between the surfaces of the heat cavity was reduced from $0.25 \mathrm{~mm}$ to $0.15 \mathrm{~mm}$, while the mass flow rate could be increased/decreased in a stable manner. The pressure seals were reinforced and a large cayity having the dimensions 56 inches $x 6$ inches was formed. Even in this case the heat source was composed of a bank of 4 electrical heaters capable of reaching approximately $2.2 \mathrm{~kW}$ each.

\subsection{Rectangular Heat Cavity Theoretical Model}

The initial design of a heat cavity with rectangular geometry ihcluded two plates locked in position by a series of eccentrics which had the purpose of changing the gap clearance during the functioning of the heat cavity. In this manner, a fine-tuning of the gap clearance would have been possible. A three-dimensional model of the rectangular heat cayity is shown in Fig. 2.1.

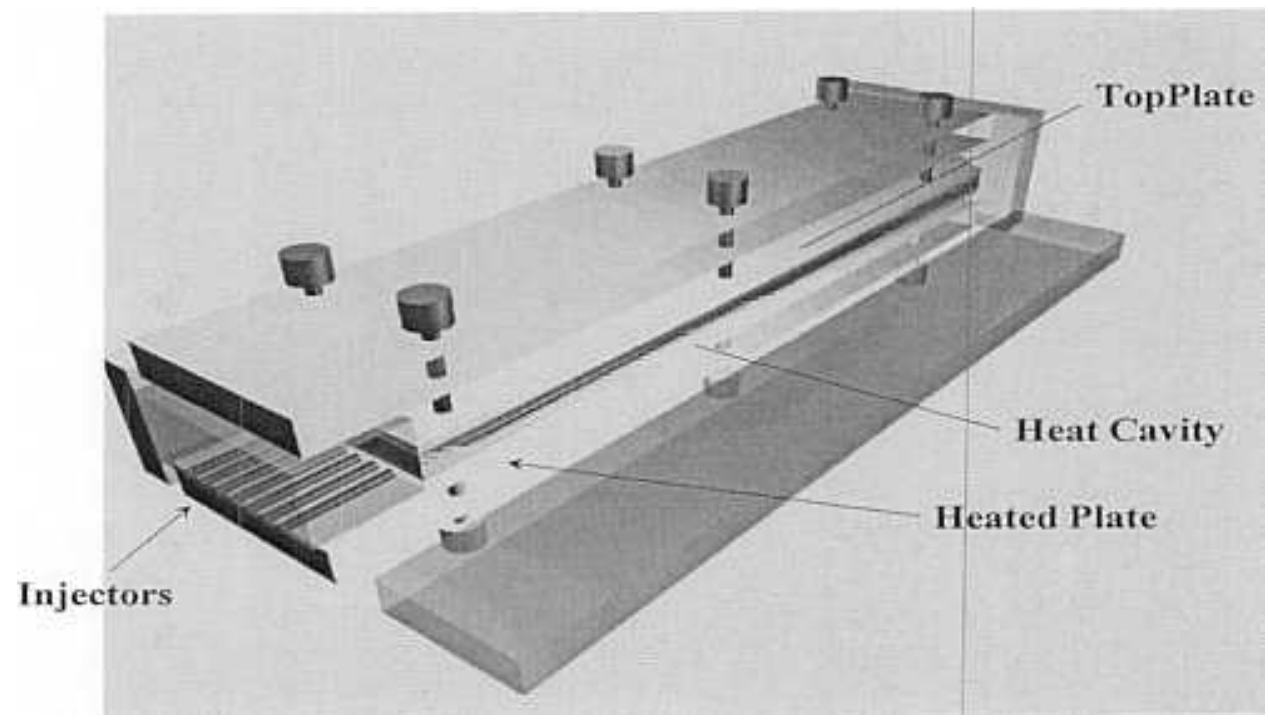

Fig. 2.1: Rectangular Heat Cavity Model

In this model, by changing the position of the cammes/eccentrics (not shown in the Figure), it is possible to lower the top plate onto the bottom plate restricting the gap to a desired clearance. In the initial design, the bottom plate contained a series of heaters imbedded at the 
bottom for a better heat transfer from heaters to plates. The combination of the top plate sandwiched with the bottom plate was designed to withstand pressure waves of $20-25$ bars peaks (294-368 psi) inside the cavity. The material forming this system is carbon-steel, which allows extensive study of the effect of gap clearance versus mass flow rate at high temperatures.

Another remarkable feature of this ideal model of heat cavity dan be shown by observing Fig. 2.2.
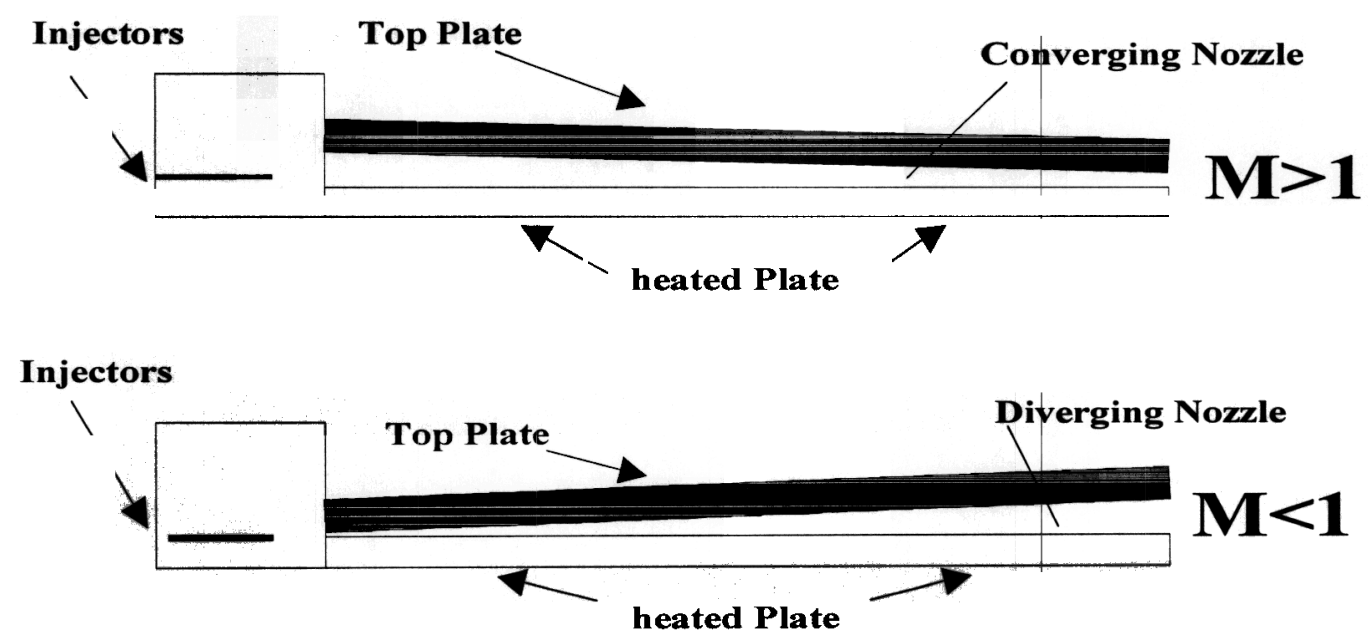

Fig. 2.2: Converging/Diverging Effects

As shown in this figure, by observing the cross-section view of the gap formed by the top and bottom plates, it is possible to create a diverging or converging nozzle effect inside the gap itself. In this manner, the steam can reach subsonic or supersonic speeds inside the heat cavity. According to calculations (shown in Appendix B), the Mach number of the steam expanding inside the cavity can vary from approximately 0.2 (subsonic flow) to 3.6 (supersonic flow). The effect of this additional parameter will be studied in the next phases of this project since the effect of the steam speed and pressure have a direct impact on the efficiency of the heat cavity/turbine combined systems. This particular feature of the rectangular heat cavity allows the combination of all of the desired effects at once to not only produce steam at the desired rate, but with an outlet velocity and pressure that would allow direct coupling with the turbine/expander. Once the ideal gap clearance is determined, the construction of heat cavities with the desired geometry could be greatly simplified. For example, once the optimized gap clearance is known, it would be easier to reassemble the concentric cylindrical heat cavity (discussed in Chapter 1) by machining the inner walls of the outer cylinder (surrounding the heat source) with a high degree of accuracy. As schematically shown in Fig. 2.3, the heat cavity inlet of the theoretical model contained the water injector/s at the extremity of the heat cavity. The water injectors were designed to spray subcooled water at room temperature with a pressure of 1,300 psi. These water injectors have the purpose of injecting water inside the heat cavity without changing the mass flow rate. As soon as water is injected inside the heat cavity, a pressure wave develops as a consequence of the steam expansion. This rapidly developing back 
pressure could affect the opening/closing of the injector varying the mass flow rate. For these reasons, the pressure of the water injected had to be several times higher than any designed pressure developing inside the heat cavity.

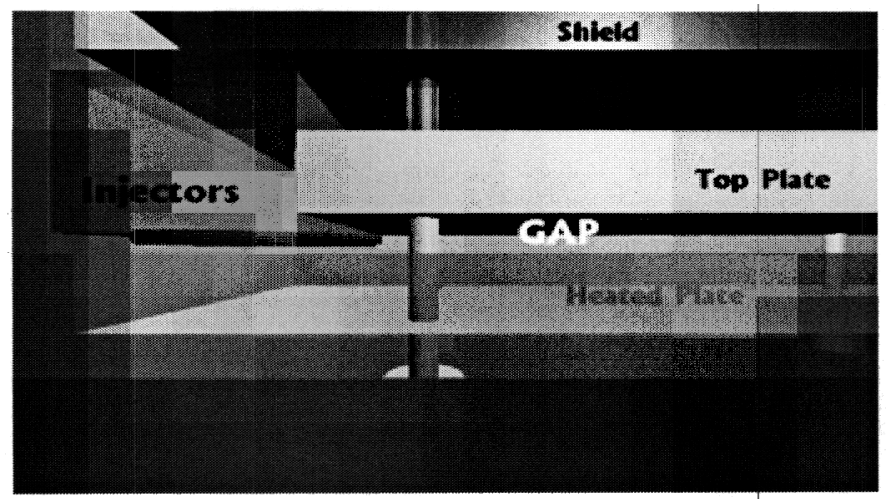

Fig. 2.3: Side View of Heat Cavity Model

\subsection{Rectangular Heat Cavity Actual Model}

The actual model of the rectangular heat cavity was derived from the ideal model with a series of modifications/restrictions mainly imposed by budget and time limitations. The main purpose of this study was to provide an empirical correlation that allows the heat cavity concept to be scaled to large power systems. In general, this investigation had the main purpose of proving the feasibility of the heat cavity concepts based on a small-scale system. However, with significant efforts, despite the severe budget limitations, it was possible to stretch Phase 2 of the proposal and overlap it with Phase 3 so as to provide not only the empirical correlation, but also a large prototype that operates with a power range close to that provided by conventional industrial power units. The actual model of the rectangular heat cavity is shown in Fig. 2.4.

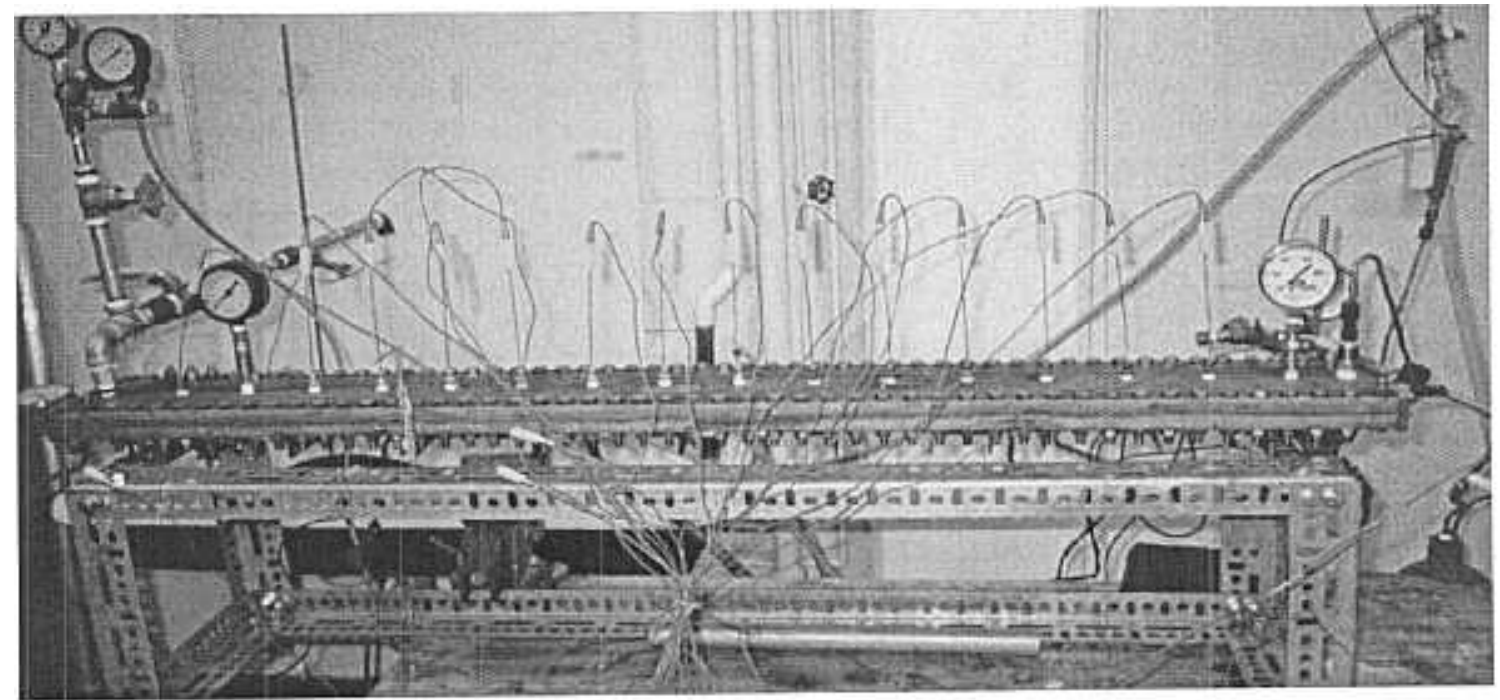

Fig. 2.4: Rectangular Heat Cavity Analog 


\subsection{Rectangular Heat Cavity Prototype Specifications}

In this model, two carbon steel plates 0.62 inch thick with the dimensions 52 inches $\mathrm{x} 6$ inches were assembled together forming a rectangular sandwich-like structure. A gap of 0.15 $\mathrm{mm}(0.0059$ inches) was maintained between the two plates by inserting two stainless steel shims on both sides. Given the dimensions of this prototype, if the pressure reaches $300 \mathrm{psi}$ inside the heat cavity, the dynamic load exerted on the surfaces of the plates would reach approximately $93,600 \mathrm{lbs}$. on each surface pushing them apart. Therefore, special sealing techniques have been utilized to avoid leakage from the sides, and about 100 steel bolts were positioned one inch apart to keep the two plates compressed one on the other to avoid warping of the structure when the pressure fluctuates inside the gap. $14 \mathrm{k}$-type thermocouples were placed 3 inches apart, and a series of pressure gauges were positioned at the cavity inlet, outlet and in various location of the gap with the purpose to monitor local pressure variations inside the gap. In Fig. 2.5 the water injectors are shown. The injector was initially positioned horizontally so as to favor the flow of water injected in the direction of the steam expanding and gaining speed toward the outlet of the cavity. However, for safety reasons, and to improve sealing of the end cups of the cavity, the injector was positioned perpendicularly to the cavity and a micro-chamber was machined right at the injector outlet to improve the dissipation of the pressure wave generated each time the injector's valve opens.

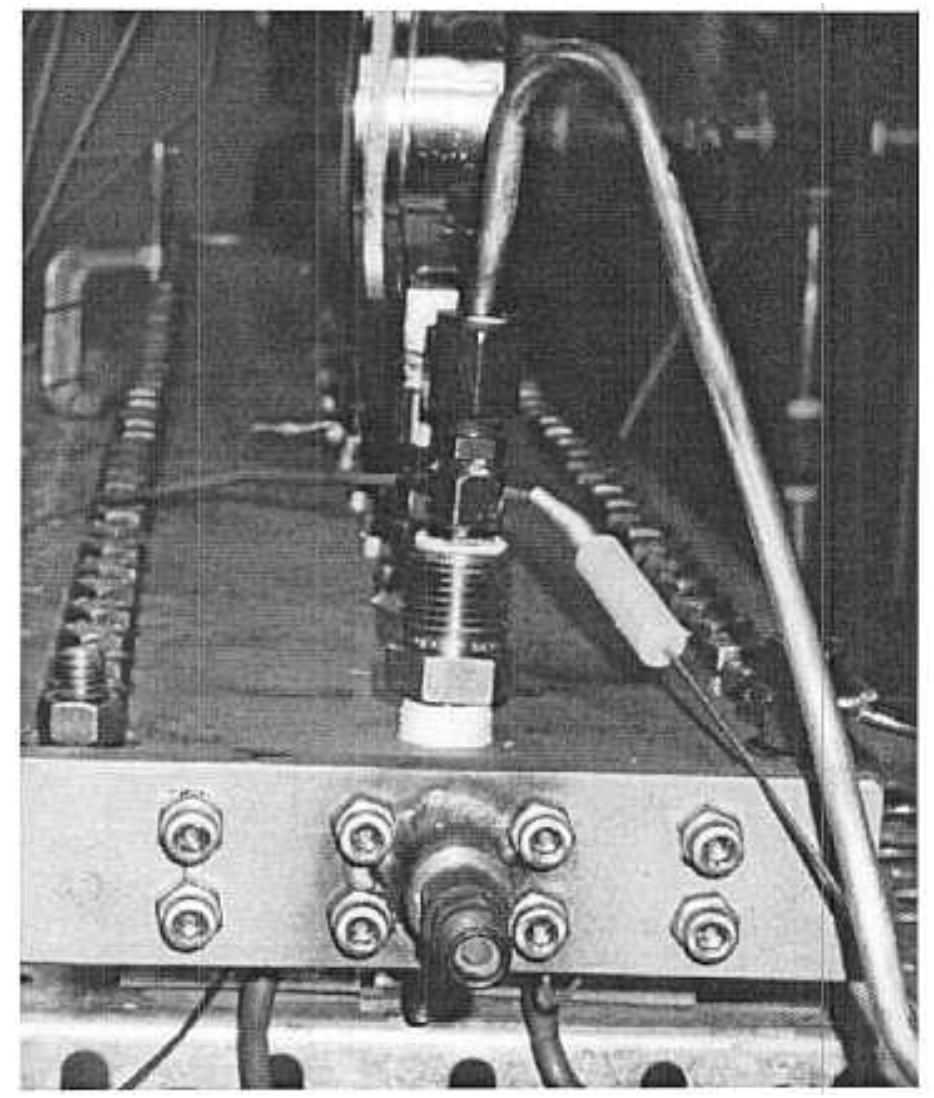

Fig. 2.5: Rectangular Heat Cavity Water Injectors 


\subsection{Experimental Set-up}

The high-pressure system was freed from all air bubbles caused mainly by cavitation at the inlet/suction of the positive displacement pump. The mass flow rate was adjusted by bleeding one of the injectors from pump discharge to pump suction. Then the current on the heaters was regulated so as to bring the heaters to a uniform temperature increase. Since the gap distance (volume of the system) was kept constant, a series of nozzles with different outlet diameters was inserted at the outlet of the heat cavity. Then the mass flow rate was varied and the various thermodynamic parameters were recorded through two synchronized data acquisition systems.

Since the heaters were not embedded inside the plates, as indicated by the ideal model, the thermal coupling between the heaters and the surfaces of the heat cavity was not optimized. In fact, by observing Table 2.1 (temperatures in ${ }^{\circ} \mathrm{C}$ ), the temperature on the heater surface is about $400{ }^{\circ} \mathrm{C}$ while on the surface of the heat cavity plate it is only about $165^{\circ} \mathrm{C}$. This represents a significant heat loss, and limits the maximum temperature on the heat cavity gap. The heaters were assembled and mechanically pressed against the bottom plate (see Fig. 2.1)

\begin{tabular}{|c|c|c|c|c|}
\hline T Heater IN & T Heater OUT & T Tank & T Plate BOTTOM & T Plate TOP \\
\hline 388.59 & 441.88 & 26.97 & \begin{tabular}{|l|l|}
164.59 & \\
\end{tabular} & 161.77 \\
\hline
\end{tabular}

Table 2.1 Heaters/Surface Temperature Difference

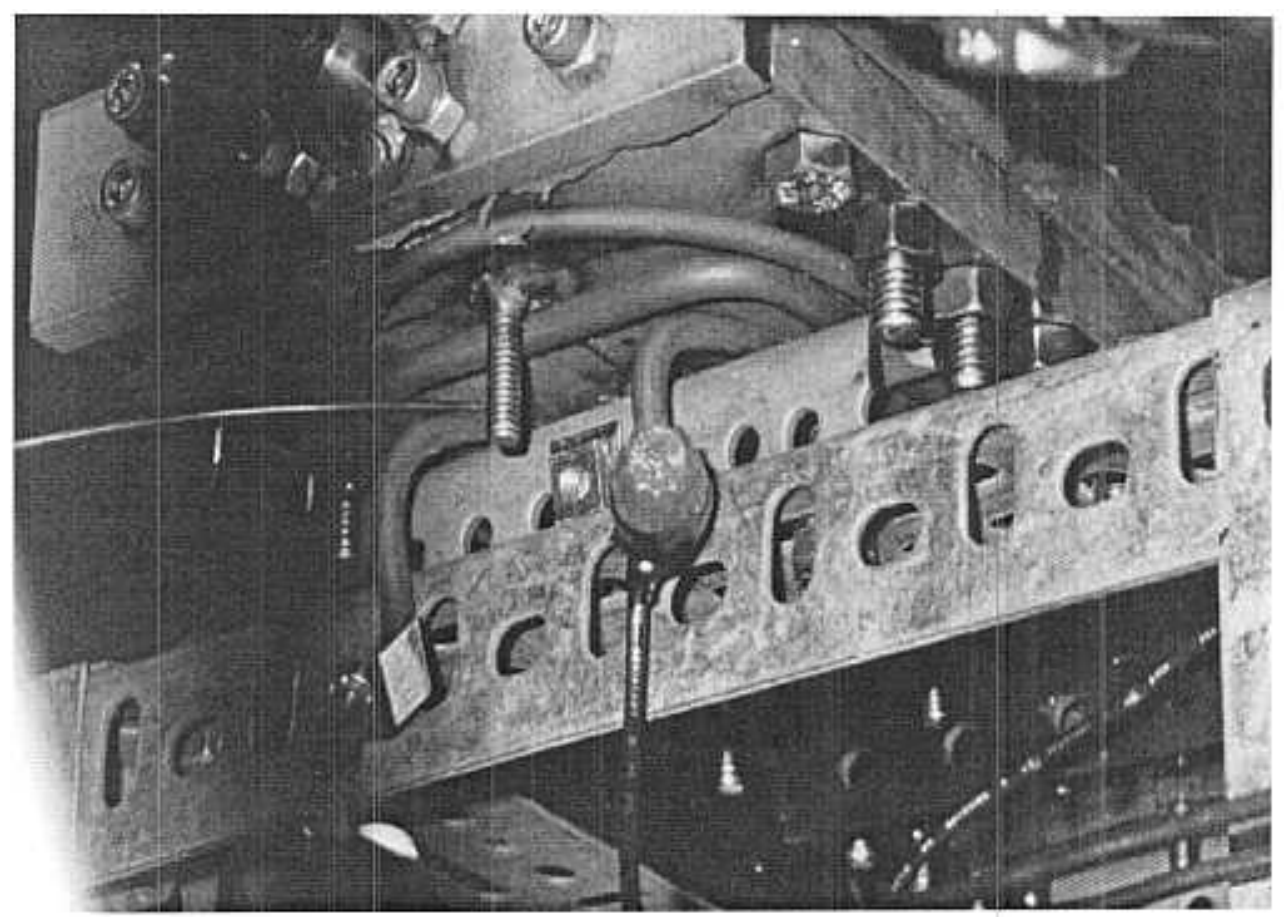

Fig. 2.6: Heaters Positioned Under the Bottom Plate 


\subsection{Experimental Results}

The first experiment on the rectangular heat cavity was conducted by inserting a nozzle 3 $\mathrm{mm}$ in diameter at the exit of the cavity. Graph 2.1 shows the temperature distribution inside the gap from the injector outlet to the cavity exit as a function of increasing mass flow rate. In this graph the temperature of the water flashing to steam inside the gap increases steadily from the injector outlet to the cavity exit. If the mass flow rate is too low (i.e. $\mathrm{m} 1=0.28 \mathrm{l} / \mathrm{m}$ and $\mathrm{m} 2=$ $0.35 \mathrm{l} / \mathrm{m}$ ) the steam reaches its maximum temperature and pressure too early inside the gap. In fact, the steam produced by injecting the mass flow rate corresponding to $\mathrm{m} 1$ and $\mathrm{m} 2$ reaches about $160^{\circ} \mathrm{C}$ after approximately 30 inches of penetration inside the cavity. On the other hand, the mass flow rate corresponding to $\mathrm{m} 6=1.6 \mathrm{l} / \mathrm{m}$ indicates a mass flow rate too large since it cools the heat cavity to about $120^{\circ} \mathrm{C}$ at 46 inches from the inlet. Another way to look at the effects of increased mass flow rates inside the heat cavity is provided by Graph 2.2. In this graph, the pressure drops too rapidly with increasing mass flow rate, thereby indicating that more heat has to be provided, the gap has to be reduced, or a smaller nozzle diameter should be inserted at the exit of the cavity.

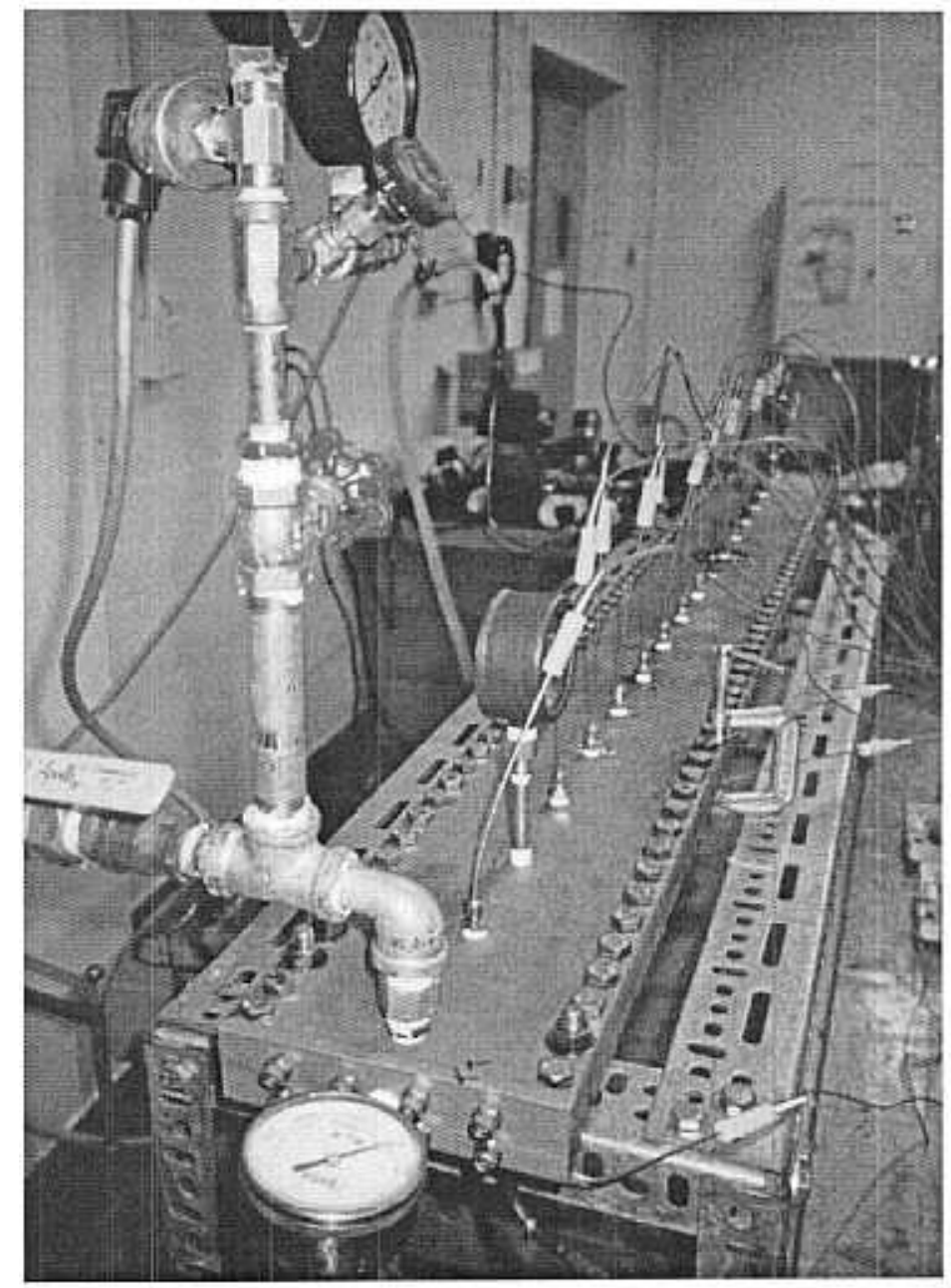

Fig. 2.7: Heat Cavity Perspective Vilew 


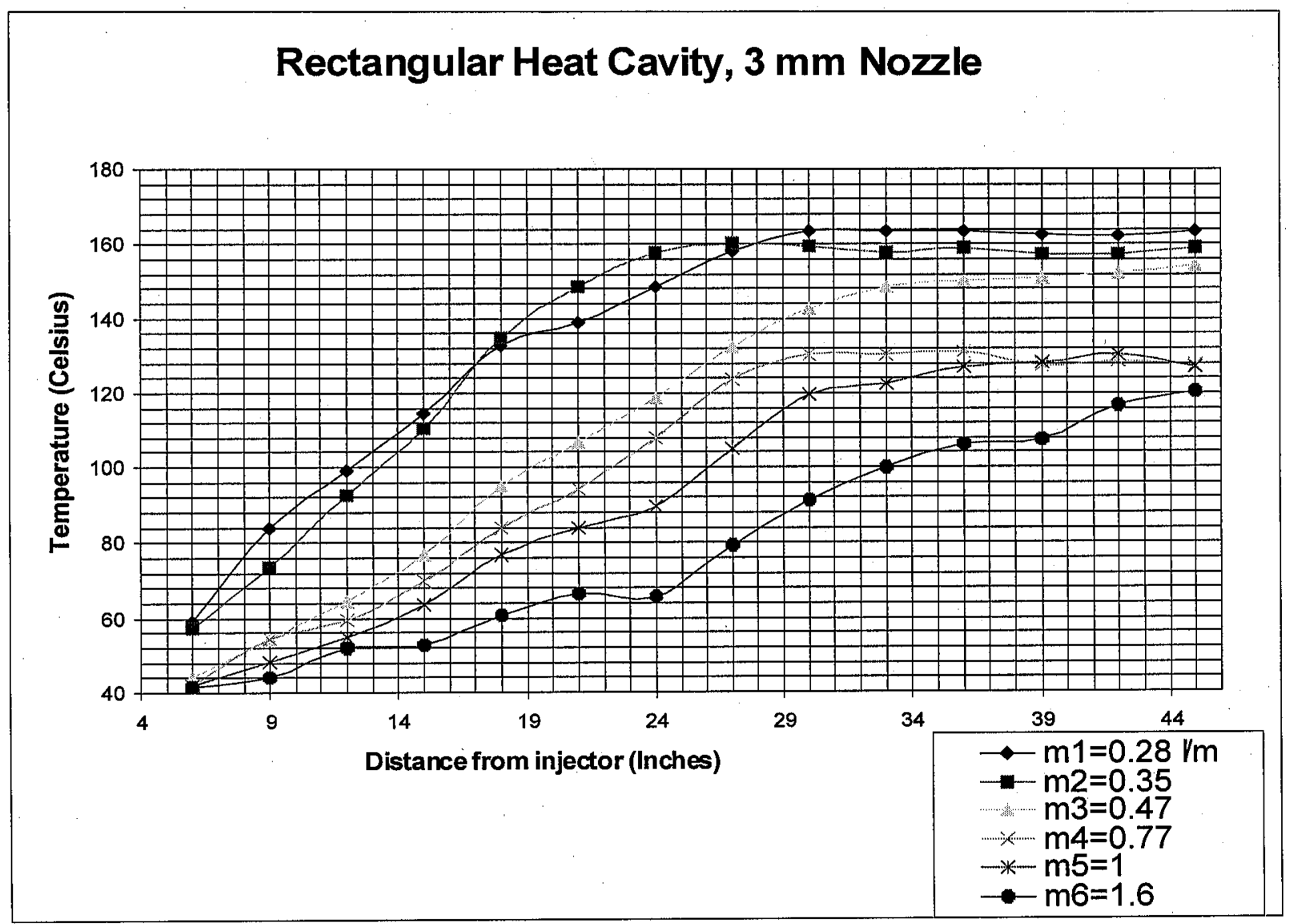

Graph 2.1: Gap Temperature Distribution Nozzle A

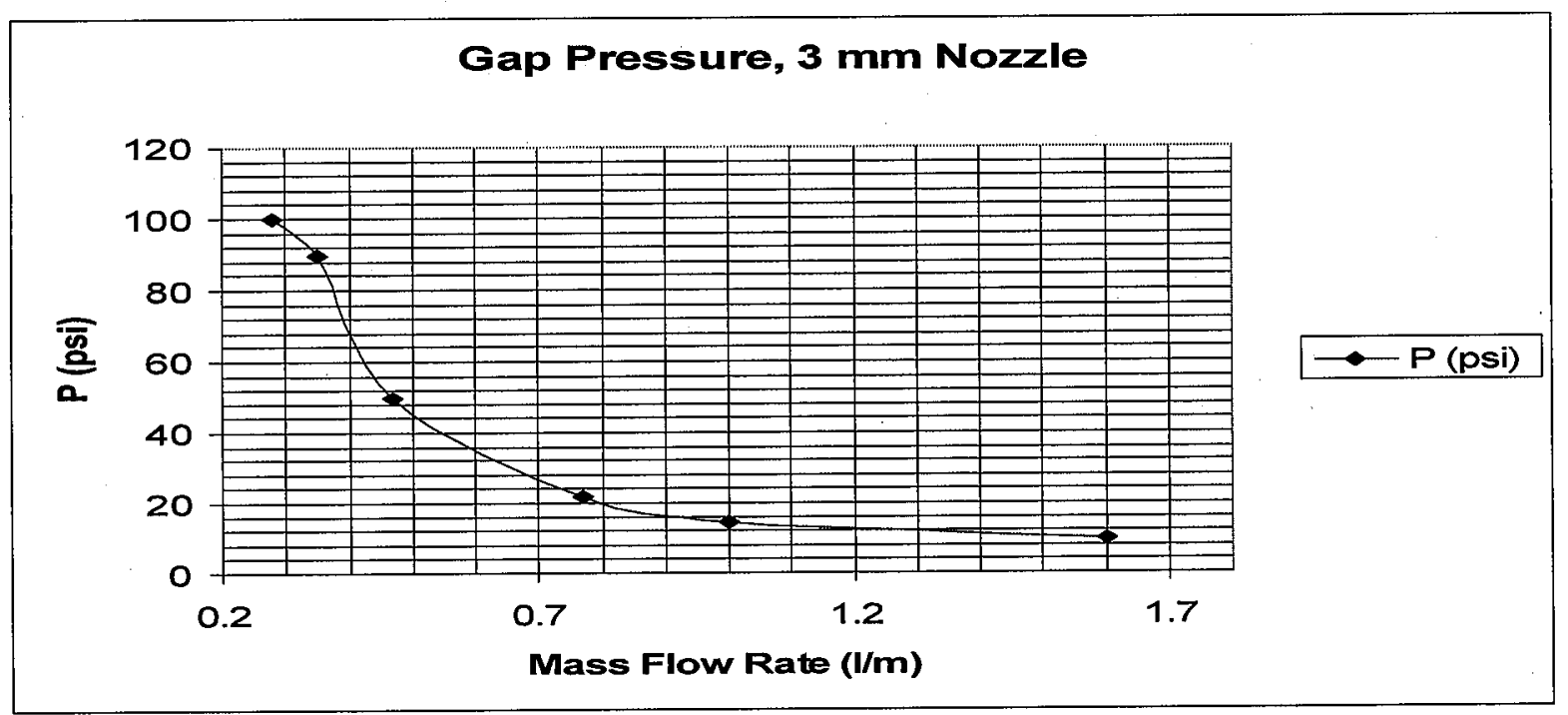

Graph 2.2: Gap Pressure Variation Nozzle A 
If the nozzle outlet nozzle is reduced, the gap pressure and temperature are immediately affected as is shown in Graphs 2.3 and 2.4 below.

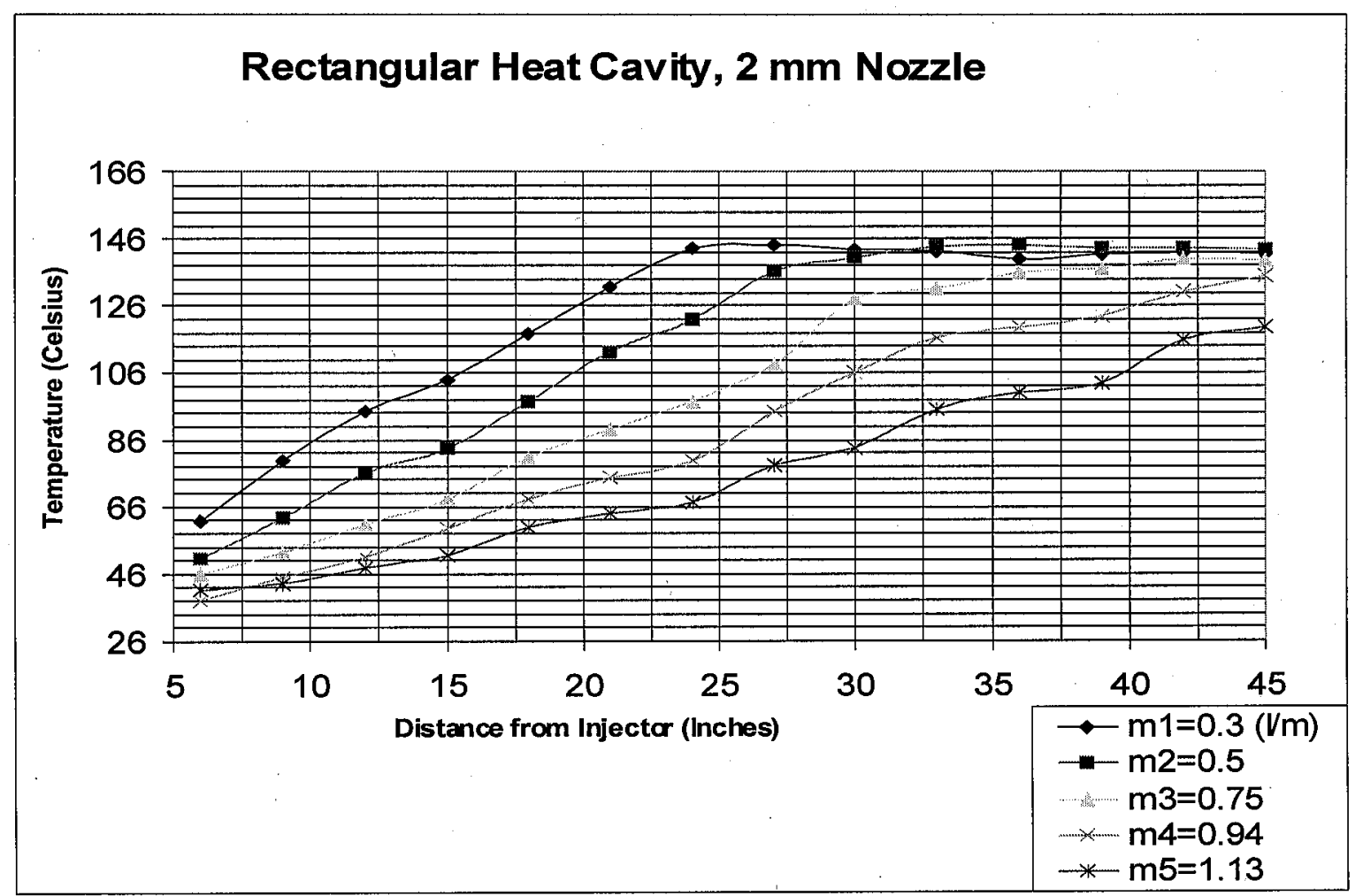

\section{Graph 2.3: Gap Temperature Distribution Nozzle B}

In this case, the nozzle diameter was reduced from $3 \mathrm{~mm}$ to $2 \mathrm{~mm}$ (Nozzle $A$ to $B$ ), and again the mass flow rate was varied. If we consider the curve representing the mass flow rate data points $\mathrm{m} 1$, when the heat cavity was operated with Nozzle B, the steam reached steady state conditions at about 23 inches from the injector outlet. When the cavity was operated with Nozzle A, the steam reached steady state conditions at approximately 28 inches from the injector outlet. By observing the pressure behavior for the heat cavity operated with Nozzle A, Graph 2.2 , and comparing it with the Graph 2.4 , it is clear that having reduced the nozzle diameter induced better performance inside the heat cavity. 


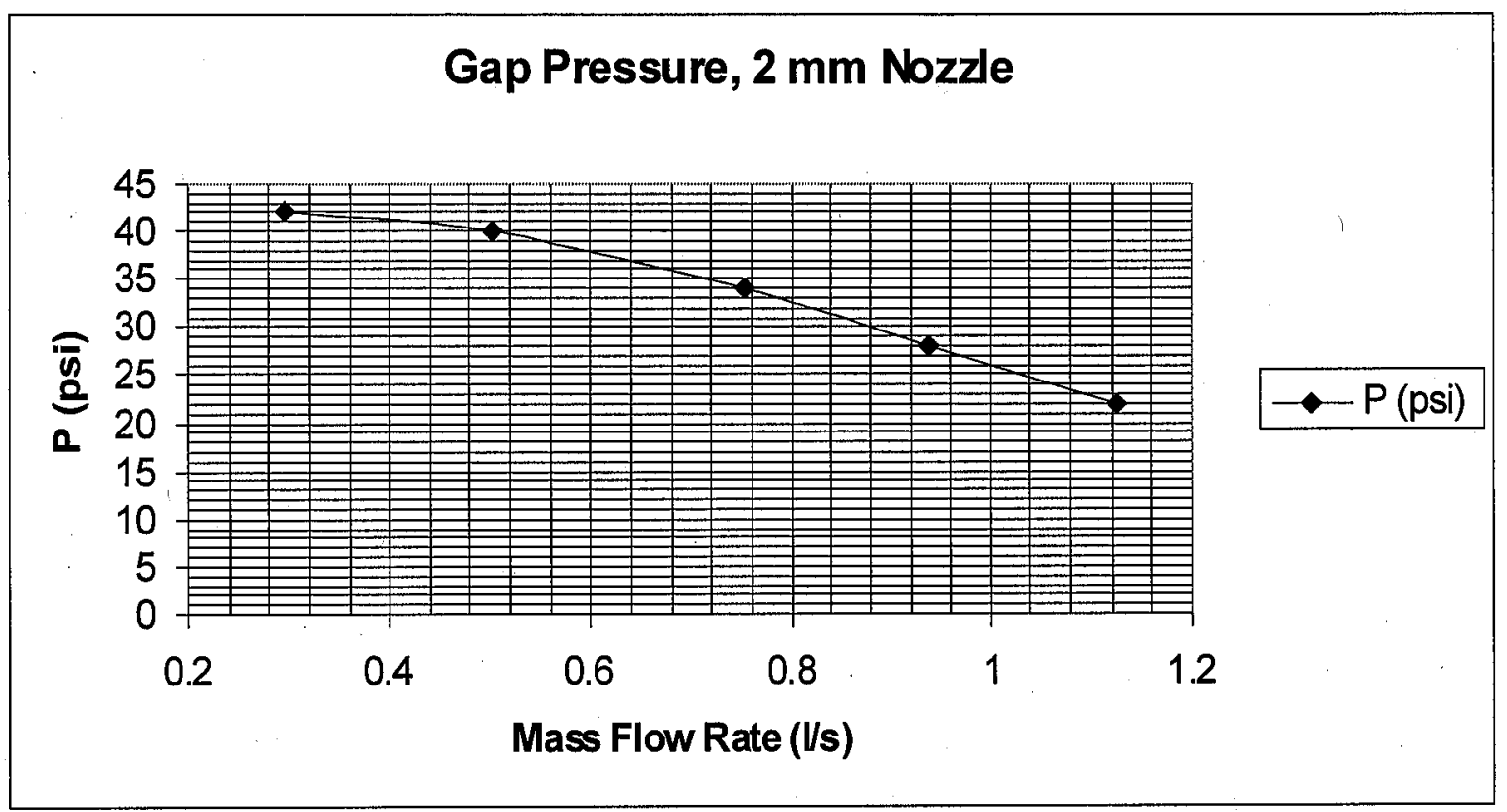

\section{Graph 2.4: Gap Pressure Variation Nozzle B}

Further reduction of the nozzle diameter produced the results plotted in Graphs 2.5 and 2.6. Again, the temperature distribution and the behavior of the pressure inside the cavity start to show a thermodynamic optimization for the given gap dimensions and heat rate. In this case, steam reaches steady state conditions even closer to the injector outlet (approximately 20 inches). In Graph 2.6 the pressure shows a dome-like behavior as the mass flow rate is increased, while in Graph 2.2 the pressure behaved significantly differently. Therefore, the optimization between the maximum pressure desired at the outlet of the heat cavity, the mass flow rate, the gap clearance, and the outlet nozzle diameter can be achieved by studying the behavior of the pressure as the mass flow rate is increased (while the heat rate is kept constant). The highest optimization of the heat cavity was finally achieved by further reducing the outlet nozzle from $1.5 \mathrm{~mm}$ to $1.17 \mathrm{~mm}$. In fact, in Graphs 2.7 and 2.8 the pressure reaches a maximum and remains at that value even when the mass flow rate is changed from 0.2 to $0.6 \mathrm{l} / \mathrm{m}$. Similarly the highest temperature with the highest mass flow rate is reached by $\mathrm{m} 3$ (Graph 2.7). Therefore, for this particular prototype, when the gap clearance is $0.15 \mathrm{~mm}$, the mass flow rate $0.2-0.6 \mathrm{l} / \mathrm{m}$, the heat cavity instantaneously transforms subcooled water at the inlet into steam at a pressure of $160 \mathrm{psi}$ and a temperature of approximately $140^{\circ} \mathrm{C}$. The tabulated data corresponding to the various graphs can be found in Appendix C. 


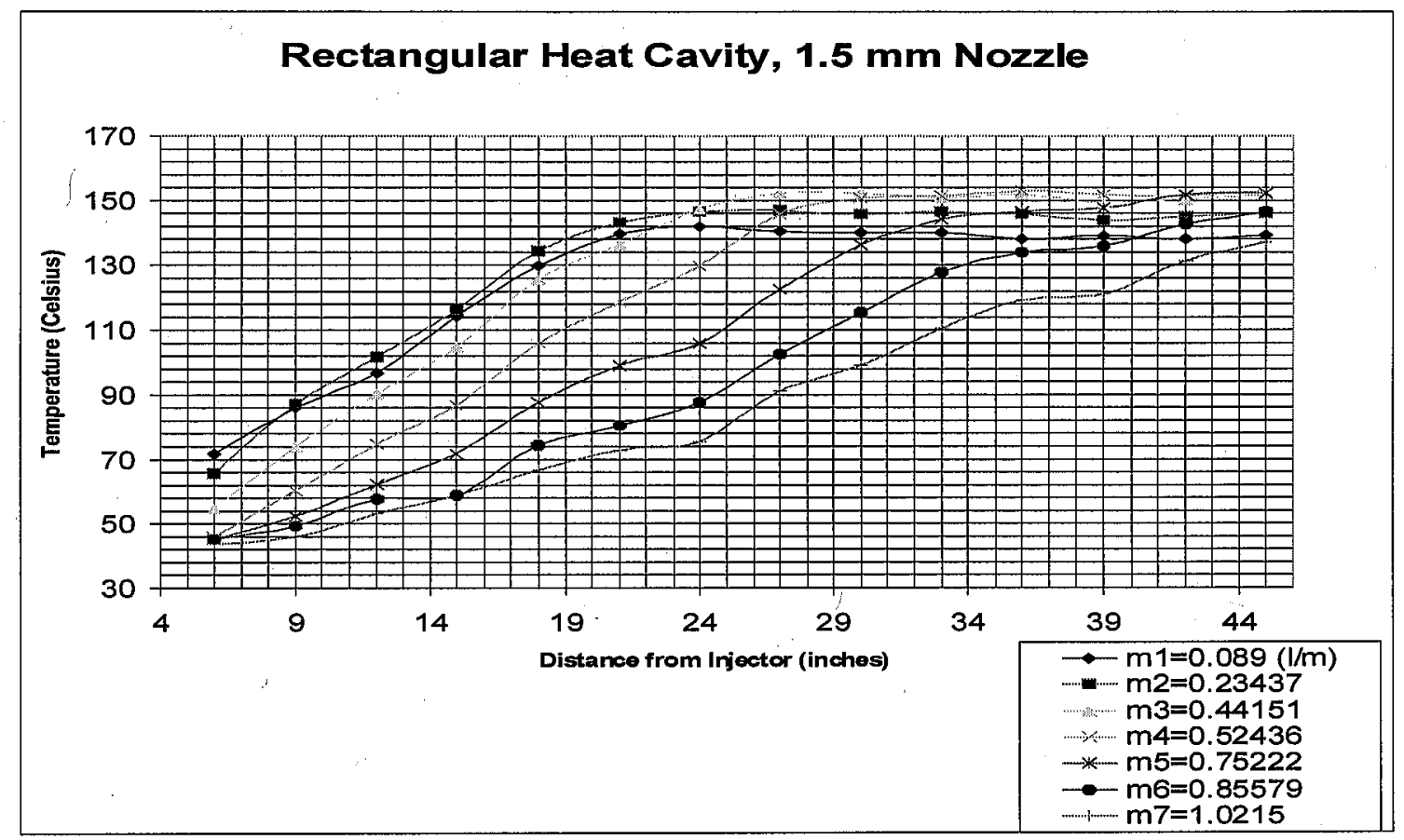

Graph 2.5: Gap Temperature Distribution Nozzle C

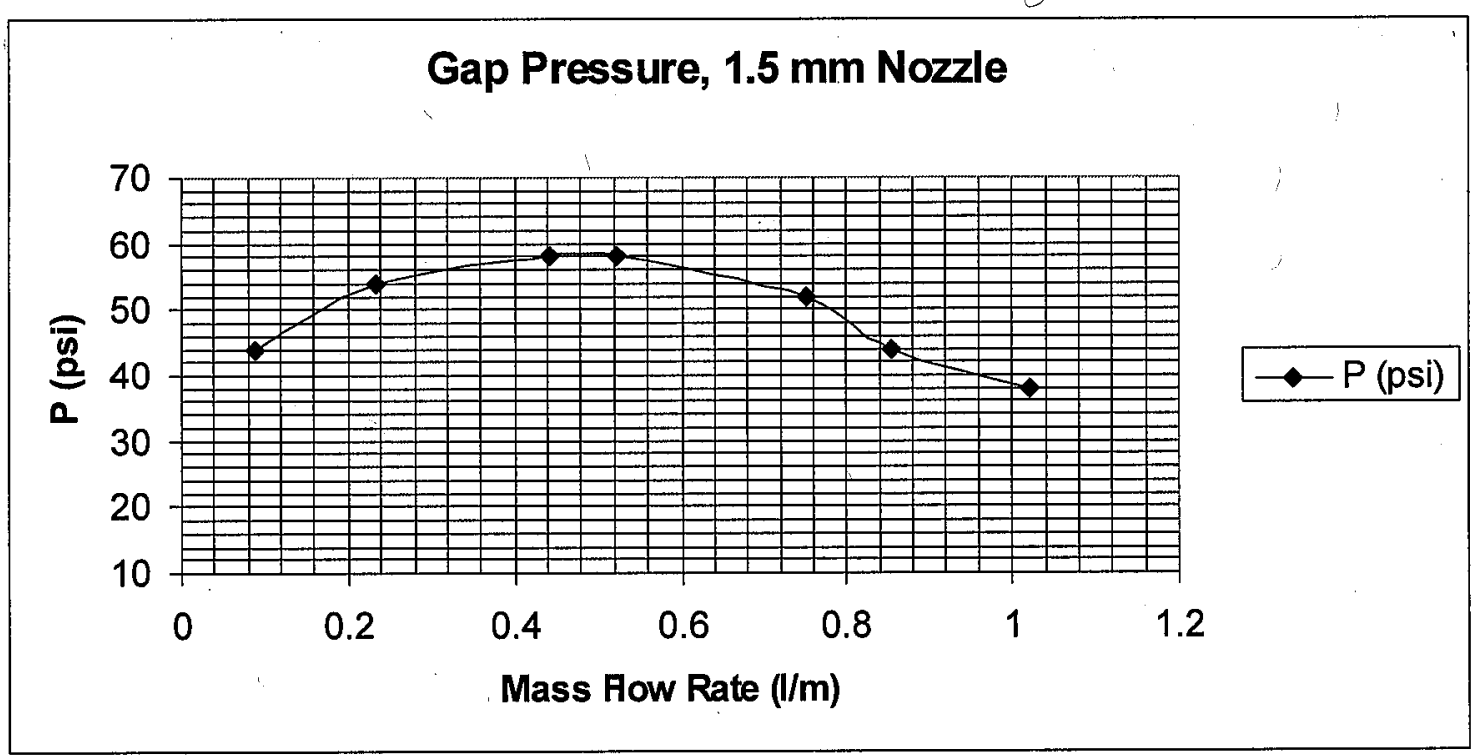

Graph 2.4: Gap Pressure Variation Nozzle C 


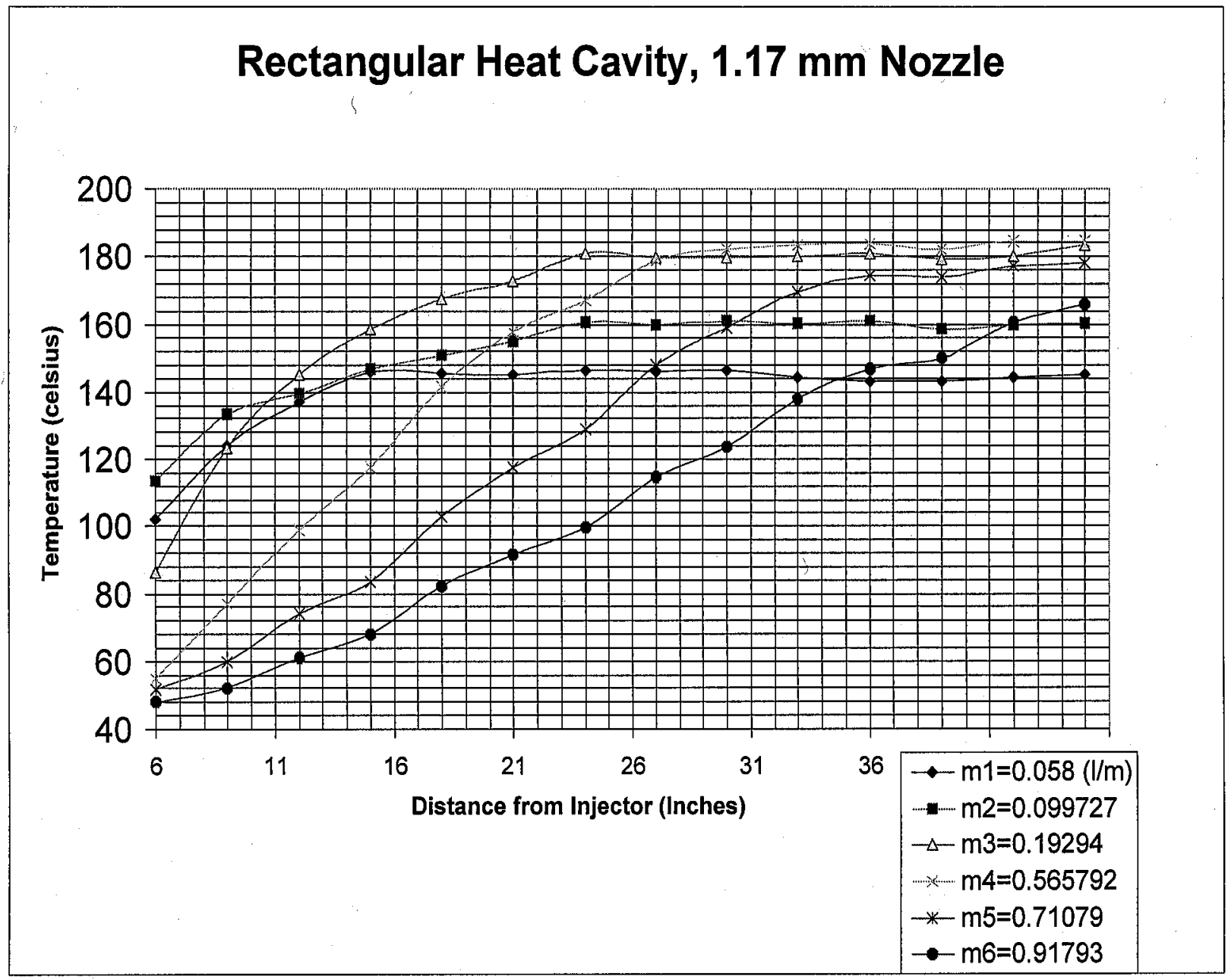

Graph 2.7: Gap Temperature Distribution Nozzle D 


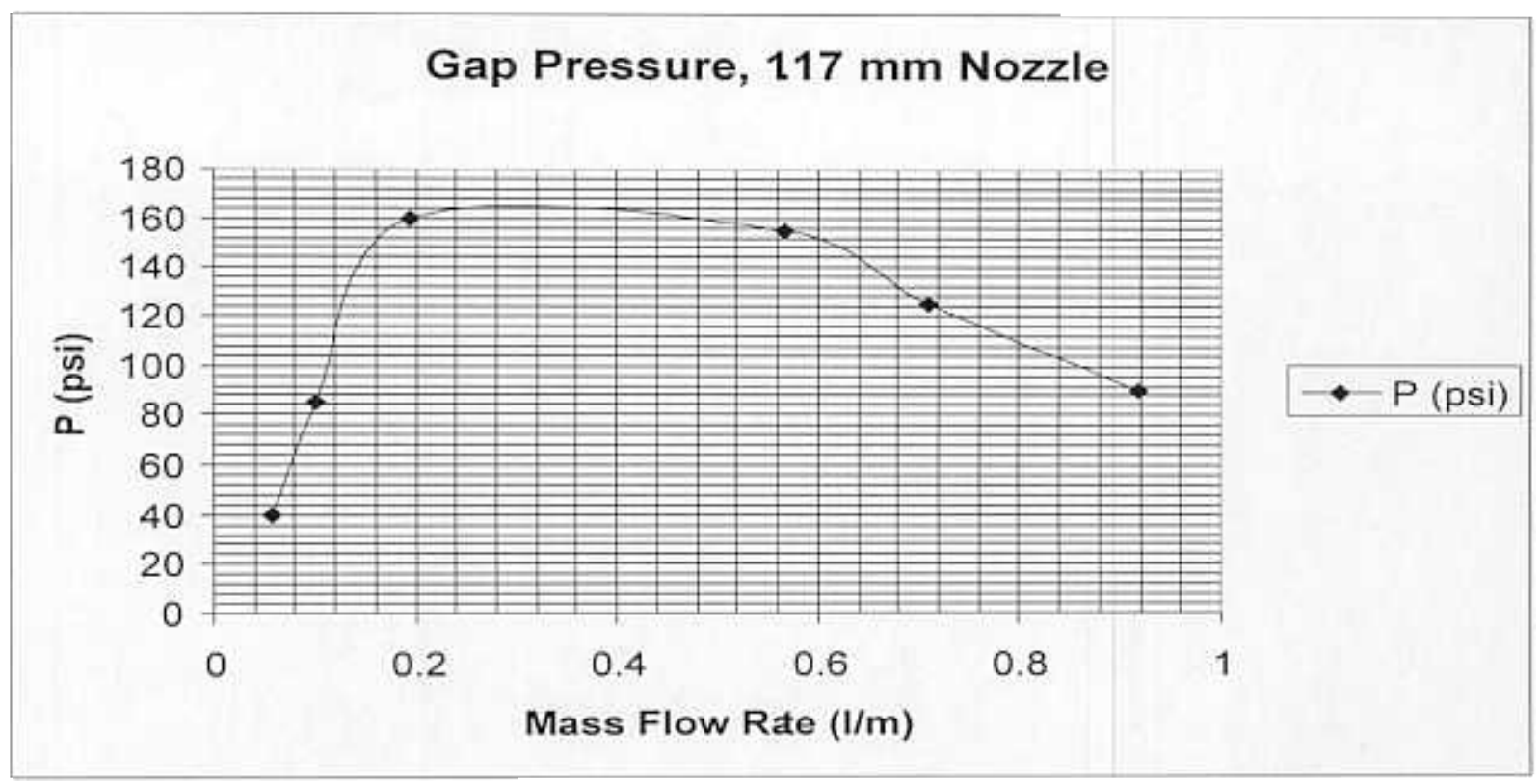

Graph 2.8: Gap Pressure Variation Nozzle C

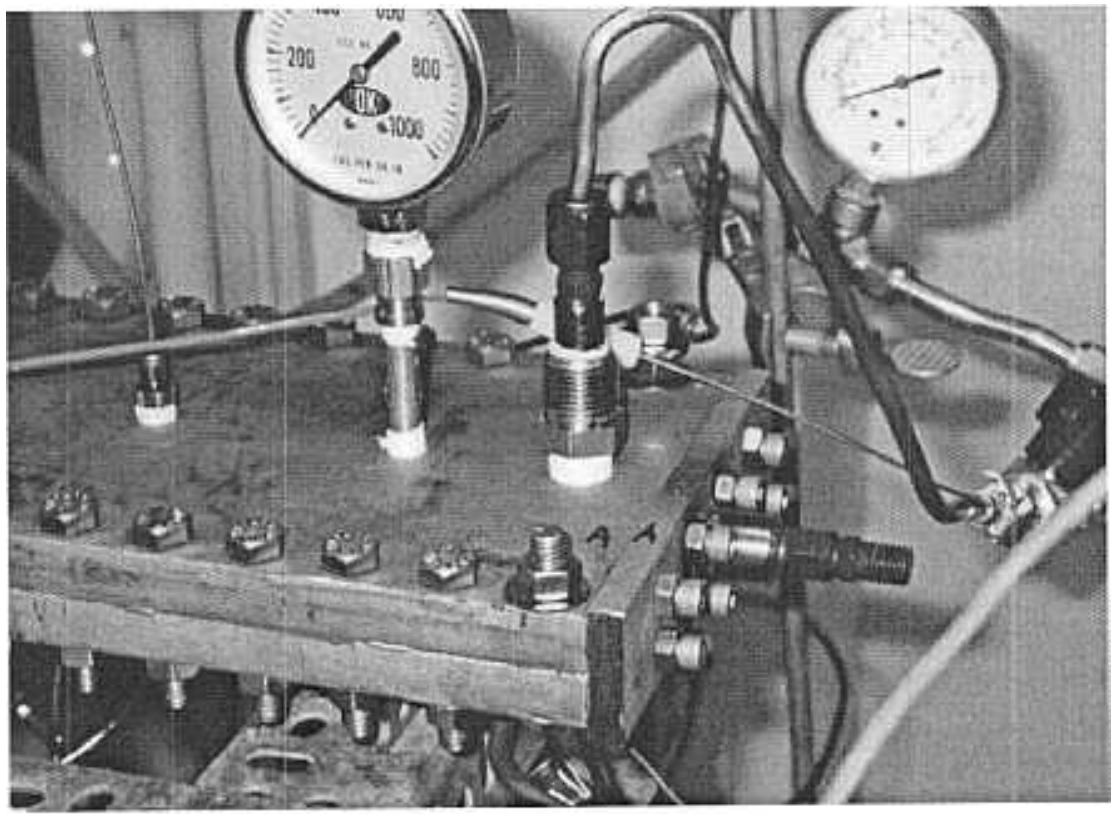

Fig. 2.8 Nozzle and High Pressure Injectors 


\subsection{Mathematical Correlation}

By considering the experimental data collected in Chapter 2, the rapid steam expansion phenomena occurring inside the gap of the heat cavity involves several more variables than the minimum variables estimated for an empirical correlation constituted by only two Pi terms. The basic variables governing the steam expansion process inside the heat cavity are:

- $\mathrm{P}$;

- $\mathrm{dQ} / \mathrm{dm}$;

- h out;

- $\mathrm{V}$;

- $\mathrm{dm} / \mathrm{dt}$;
Pressure

Heat Rate

Enthalpy at Nozzle Exit

Volume

Mass Flow Rate (psi)

$(\mathrm{kJ} / \mathrm{kg})$

$(\mathrm{kJ} / \mathrm{kg})$

$\left(\mathrm{m}^{3}\right)$

$(\mathrm{kg} / \mathrm{s})$

The gap clearance can be extrapolated by knowledge of the cavity volume (variable V $\left(\mathrm{m}^{3}\right)$ ) since the volume is dependent on the distance between the two concentric cylinders (cylindrical heat cavity), or the distance between the surfaces of the two plates (rectangular heat cavity). The enthalpy can be calculated by knowledge of at least two properties (i.e. pressure and temperature). All of the other variables can be directly determined from the experiment.

A simplified correlation, utilizing only two dimensionless Buckingam Pi terms, is reported below:

$$
\subseteq_{1}=\Phi ?\left(\complement_{2}\right)
$$

Where $\Pi_{1}$ and $\prod_{2}$ are:

$$
\frac{\mathrm{P} ? \sqrt{h}}{V^{\frac{1}{3}} ? \stackrel{?}{Q}}=\Phi ? \frac{\bar{m} ? \stackrel{?}{h} \sqrt{?}}{V ? \stackrel{Q}{Q}}
$$

The $\Phi$ function is the objective, and the accuracy of the mass flow rate determination is crucial to the accuracy of the overall correlation. By adding more variables the correlation's accuracy would increase, and more than two Pi terms would be required. At this stage of the investigation it is sufficient to obtain an empirical mathematical tool that serves only as an approximation. Additional testing on the actual prototypes, and the utilization of more sophisticated instrumentation (particularly for the mass flow rate) will allow the determination of a more refined correlation. Other factors could also be included in the correlation. For example, the roughness of the carbon-steel plate surfaces was not taken into account in the $\Pi_{1}$ and $\Pi_{2}$ terms, and given the extremely narrow gap $(0.15 \mathrm{~mm})$, the roughness of the surface surely plays an important role in the expansion phenomena. Another factor that gives a better idea of the coarse nature of the empirical correlation is given by observing that the mass flow rate measurements showed a $+/-25 \%$ instrumental error. As it was explained in Chapter 1 , for the cylindrical and rectangular heat cavities, a minor variation of the mass flow rate causes significant variations in the pressure inside the gap. Thus, the mathematical correlation derived 
in the following paragraphs is only indicative. A more reliable and realistic way to deduce the behavior of the heat cavity can be extrapolated by observing the plots reported in Chapter 2 .

\subsection{Determination of the $\Pi$ terms}

Given the dimensions of the rectangular heat cavity and the high risk of damaging the structure and/or seals in case of prolonged pressure fluctuations, the gap clearance was kept constant $\left(\mathrm{V}=\right.$ constant $\left.=1.896 \mathrm{E}-5 \mathrm{~m}^{3}\right)$, while the steam pressure was regulated by changing the nozzle diameter at the outlet of the cavity. Four nozzle diameters were investigated:

- Nozzle A: $3 \mathrm{~mm}$

- Nozzle B: $2 \mathrm{~mm}$

- Nozzle C: $1.5 \mathrm{~mm}$

- Nozzle D: $1.17 \mathrm{~mm}$

By utilizing the numerical values reported in Table 3.1,3.2, 3.3, and 3.4, a specific correlation, in the form of a polynomial or exponential expression, can be derived per each nozzle diameter. The software Engineering Equation Solver (EES), was utilized to compute the numerical values of the $\Pi$ terms, and also for the thermodynamic evaluation of steam properties at the various conditions inside the cavity. Table 3.5 shows the thermodynamic evaluation for the steam exiting the $1.17 \mathrm{~mm}$ diameter nozzle when the pressure developed inside the heat cavity is 6.2 bars. In this first evaluation the effect of the speed of steam exiting the cavity and the heat losses are neglected. The theoretical value of the heat transfer rate $Q$ is also reported in Table 3.5. This value of $Q$ represents the heat to be added to the system to transform subcooled liquid water at the inlet into steam at the outlet temperature and pressure.

\begin{tabular}{|r|r|r|r|r|r|}
\hline 3 mm Nozzle & \multicolumn{5}{|l|}{} \\
\hline$\phi(\Pi 1)$ & \multicolumn{1}{|c|}{$\Pi 2$} & dm/dt $(1 / \mathrm{m})$ & $\mathrm{P}$ (bar) & hout $(\mathrm{kJ} / \mathrm{kg})$ & $\mathrm{Q}(\mathrm{kJ} / \mathrm{s})$ \\
\hline 66484 & 2664 & 0.28 & 6.9 & 688.2 & 2.55 \\
\hline 66971 & 1956 & 0.35 & 6.2 & 669.5 & 3.076 \\
\hline 55598 & 331 & 0.47 & 3.45 & 2767 & 20.56 \\
\hline 55641 & 89.15 & 0.77 & 1.51 & 2727 & 33.17 \\
\hline 55637 & 44.97 & 1 & 0.99 & 2731 & 43.15 \\
\hline 55649 & 19.63 & 1.6 & 0.69 & 2721 & 68.75 \\
\hline
\end{tabular}

Table 3.1: Nozzle A

$2 \mathrm{~mm}$ Nozzle 


\begin{tabular}{|r|r|r|r|r|r|}
\hline \multicolumn{1}{|c|}{$\phi(\Pi 1)$} & \multicolumn{1}{|c|}{$\mathrm{dm} \mathrm{dm} / \mathrm{dt}(\mathrm{l} / \mathrm{m})$} & $\mathrm{P}(\mathrm{bar})$ & hout $(\mathrm{kJ} / \mathrm{kg})$ & $\mathrm{Q}(\mathrm{kJ} / \mathrm{s})$ \\
\hline 55642 & 454.7 & 0.069 & 0.69 & 2726 & 2.97 \\
\hline 55623 & 441.8 & 0.297 & 2.9 & 2743 & 12.88 \\
\hline 55619 & 249.9 & 0.5 & 2.76 & 2747 & 21.7 \\
\hline 55622 & 141.3 & 0.75 & 2.34 & 2744 & 32.53 \\
\hline 55629 & 93.13 & 0.94 & 1.93 & 2738 & 40.67 \\
\hline 55660 & 60.95 & 1.13 & 1.51 & 2711 & 48.37 \\
\hline
\end{tabular}

Table 3.2: Nozzle B

\begin{tabular}{|c|c|c|c|c|c|}
\hline 1,5 mm Nozzle & & & & & \\
\hline$\phi(\Pi 1)$ & $\Pi 2$ & $\mathrm{dm} / \mathrm{dt}(\mathrm{l} / \mathrm{m})$ & $\mathrm{P}$ (bar) & hout $(\mathrm{kJ} / \mathrm{kg})$ & $Q(\mathrm{~kJ} / \mathrm{s})$ \\
\hline 55630 & 1546 & 0.089 & 3.033 & 2737 & 3.866 \\
\hline 55620 & 719.9 & 0.234 & 3.72 & 2746 & 10.15 \\
\hline 55609 & 410.8 & 0.44 & 3.999 & 2756 & 19.17 \\
\hline 55606 & 344.5 & 0.524 & 3.999 & 2761 & 32.83 \\
\hline 55604 & 215.2 & 0.752 & 3.585 & 2753 & 37.23 \\
\hline 55631 & 116.4 & 1.02 & 2.62 & 2736 & 44.16 \\
\hline
\end{tabular}

Table 3.3: Nozzle C

\begin{tabular}{|r|r|r|r|r|r|}
\hline 1,17 mm Nozzle & \multicolumn{1}{|l|}{} \\
\hline$\phi(\Pi 1)$ & \multicolumn{1}{|c|}{$\Pi 2$} & $\mathrm{dm} / \mathrm{dt}(\mathrm{l} / \mathrm{m})$ & $\mathrm{P}$ (bar) & hout $(\mathrm{kJ} / \mathrm{kg})$ & $\mathrm{Q}(\mathrm{kJ} / \mathrm{s})$ \\
\hline 55613 & 2139 & 0.0583 & 2.76 & 2753 & 2.523 \\
\hline 55605 & 2654 & 997 & 5.9 & 2760 & 4.35 \\
\hline 66807 & 6267 & 0.193 & 11.04 & 777 & 2.042 \\
\hline 55575 & 293.5 & 0.57 & 10.7 & 2783 & 24.92 \\
\hline 55593 & 304.2 & 0.72 & 8.62 & 2782 & 31.23 \\
\hline 66807 & 6267 & 0.92 & 6.21 & 2771 & 40.3 \\
\hline
\end{tabular}

Table 3.4: Nozzle D 


\begin{tabular}{|c|c|}
\hline 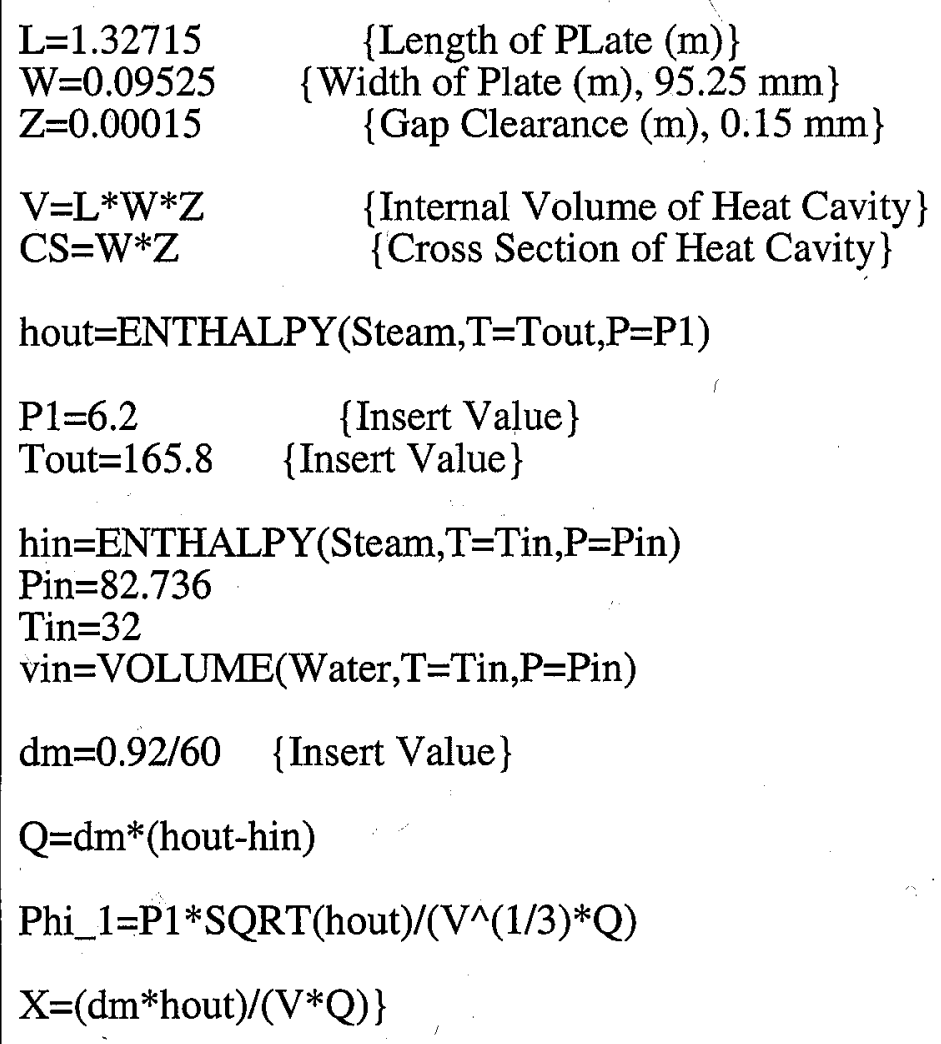 & $\begin{array}{l}\mathrm{CS}=0.00001429[\mathrm{~m} 2] \\
\mathrm{dm}=0.01533[\mathrm{~kg} / \mathrm{s}] \\
\text { hin=142.3[kJ/kg] } \\
\text { hout=2771[kJ/kg] } \\
\mathrm{L}=1.327[\mathrm{~m}] \\
\mathrm{P} 1=6.2[\mathrm{bar}] \\
\mathrm{Phi} 1=303.7 \\
\mathrm{Pin}=82.74[\mathrm{bar}] \\
\mathrm{Q}=40.3[\mathrm{~kJ} / \mathrm{s}] \\
\text { Tin=32[C] } \\
\text { Tout=165.8 [C] } \\
\mathrm{V}=0.00001896[\mathrm{~m} 3] \\
\text { vin=0.001005 [m3/kg] } \\
\mathrm{W}=0.09525[\mathrm{~m}] \\
\mathrm{X}=55593 \\
\mathrm{Z}=0.00015[\mathrm{~m}]\end{array}$ \\
\hline
\end{tabular}

Table 3.5: Single Point EES Computation 


\subsection{Conclusions and Recommendations}

Preliminary analyses of two heat cavities were performed with the purpose of determining a correlation between the key parameters governing rapid steam expansions inside narrow gaps, and the feasibility of a large scale system to be coupled with conventional expanders (i.e. turbines). While limits in some of the parameter determinations have been identified during the analysis, the results presented are sufficient to represent a best-estimate prediction of the thermal-hydraulic behavior expected in the heat cavity during constant pressure operation as well as during pressure fluctuations.

In general, the predictions of the behavior of the rectangular heat cavity were reasonable given the equipment utilized and the timeframe of this grant. Most importantly, the results obtained from the two prototypes, and in particular the rectangular heat cavity, show that controlled steam explosions are feasible and constitute a more efficient way to transfer energy from the heat source to the work-producing unit.

Continued research and collection of more data points are necessary to optimize the empirical correlation derived in this study. Phases 3, 4 and 5 of this proposal would provide the needed data to do this, and ultimately bring the heat cavity idea to fruition. 


\section{Heat Transfer Mechanisms in the Heat Cavities}

In the redesigned engine head, each heater is inserted inside a hole machined in the head block and vented to the expansion chamber so as to form a concentric tube annulus. In this configuration, the high pressure water injector is hydraulically connected to the gap formed by the concentric tubes through a pre-chamber named injector chamber as shown in Fig. 5.8.

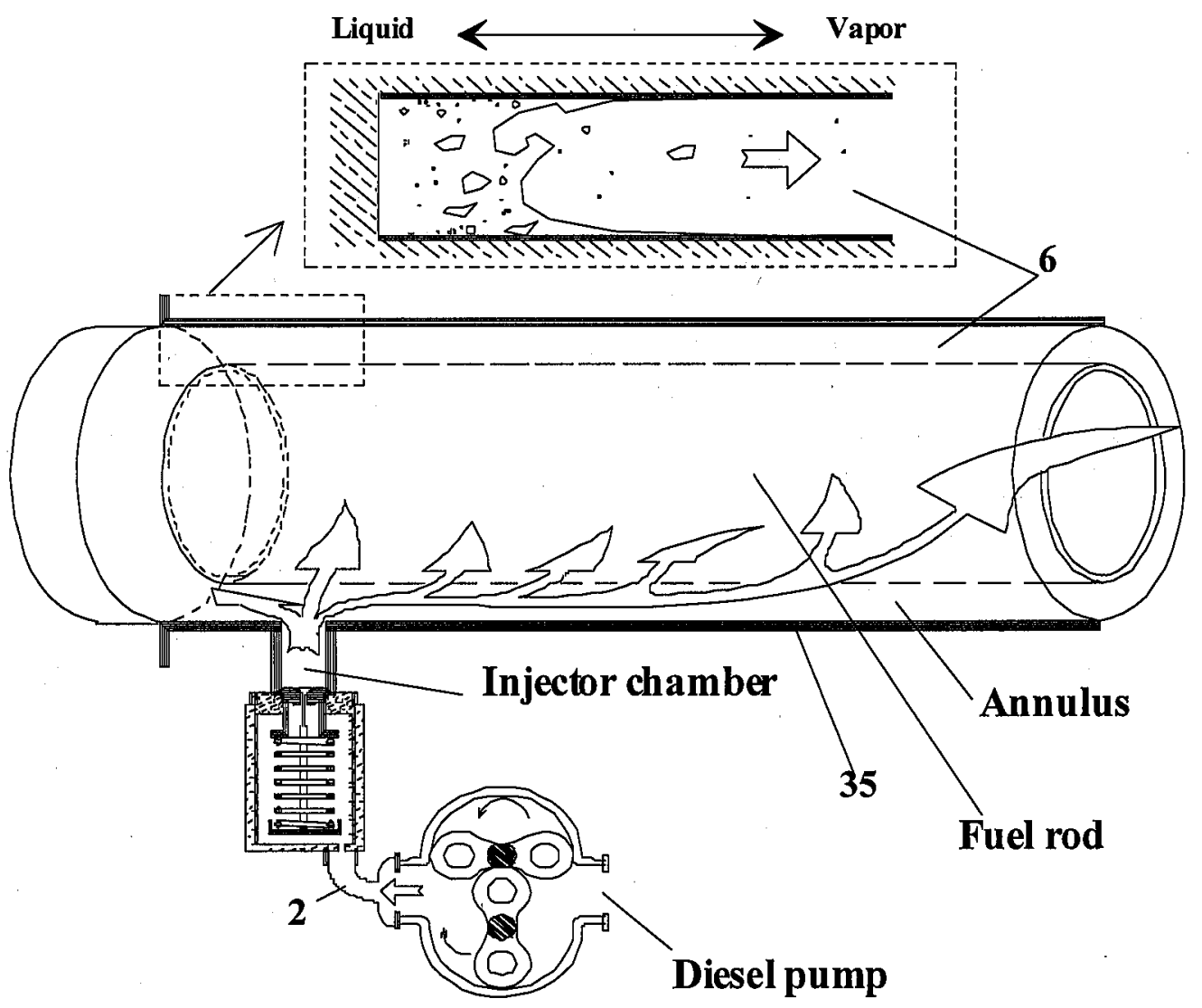

Figure 5.8: Heat transfer mechanisms in the gap

The coolant flow path from the injector chamber to the expansion chamber [36] is through the gap or annulus [6] formed by the heater [7] and the surrounding wall [35].

The heat cavity is designed so that the only way out for the injected fluid mass is through the annulus. The injection phase occurs only when the pressure in the discharge tube [2] is about 90 bars, and persists as long as imposed (by the number of injection crank $^{\circ}$ ) regardless of any pressure value eventually developed in the injector chamber and the adjacent annulus (the piston-cylinder maximum pressure is much lower than the injectors pressure, 20 bars versus 90 bars).

Since the heat addition process starts as soon as the first coolant drops enter the injector chamber and consequently the annulus, it is the subsequent fast fluid expansion 
process itself that provides the driving force which pushes the fluid out of the cavity into the expansion chamber [36]. The heat transfer mechanisms taking place along the annulus while the fluid expands through the cavity and finally in the expansion chamber are to some extent the same mechanisms analyzed for two-phase forced convection boiling in which some two-phase flow definitions are now borrowed and slightly modified to describe the various steps of the particular expansion process occurring in the annulus.

The following is a description, determined through observation and measurement, of the heat transfer mechanisms occurring in the heat cavities of the NPSEE from the injection phase to the final expansion in the expansion chamber:

- Single phase sub-cooled liquid-Prior to the opening of the injector valve, the coolant is compressed liquid at a pressure of 90 bars and a temperature of $230^{\circ} \mathrm{C}$. Since $\mathrm{T}_{\text {sat }(\mathrm{P}=90 \text { bars })}=303^{\circ} \mathrm{C}$, there is no vapor phase formation in this compressed liquid phase.

- Two-phase liquid vapor mixture-Right at the opening of the injector valve the system pressure drops to 5 bars and heat starts to be transferred to the first droplets of fluid entering the injector chamber. In particular, at $R p M=227$, the steam quality at this stage of the expansion process is about $54.2 \%$ (denoted by the symbol $\mathrm{X}_{1}$ in the thermodynamic analysis).

- Churn flow-Steam is rapidly forming upon contact with the hot surfaces of the injector chamber walls and the part of the annulus exposed to the injector spray. The steam that has formed acts as an obstacle to the incoming fluid droplets being sprayed in the injector chamber. Then a highly irregular and unstable flow pattern, mainly consisting of bubbles that mix with the incoming relatively cold fluid injected, starts to occupy the volume of the injector chamber and enter the annulus. Meanwhile, the pressure in the injector chamber, the annulus and the expansion chamber begins to rise.

- Annular flow and mist (or drop) flow-The two-phase flow entering the annulus and surrounding the heater surface becomes almost instantaneously a single phase super-heated vapor with some entrainment of droplets coming from the decaying injection phase. Some of the fluid enters deep into the annulus path in which further heat is added. At this point there is the complete evaporation of local liquid films formed by the local compression of the fluid as a result of the "explosive" nature of this heat transfer mechanism.

- Single-phase vapor-The annulus is now occupied by super-heated vapor which is expanding at an extremely fast rate (consider that the fluid density changes from $1000 \mathrm{~kg} / \mathrm{m}^{3}$ to $6.342 \mathrm{~kg} / \mathrm{m}^{3}$ in about $15 \mathrm{~ms}$, see $\mathrm{v}_{01}$ and $\mathrm{v}_{02}$ in the thermodynamic analysis in Chapter 2).

Therefore, as soon as the injection phase terminates, the original liquid fluid has been completely converted to a super-heated vapor accelerating through the annulus toward the expansion chamber [36].

\subsection{NPSEE Heat Cavity: Velocity at the Exit}


The annulus becomes essentially a nozzle to which heat is continuously added during the whole process. Furthermore, since the overall annulus exit cross sectional area is fixed, the velocity of the flow is forced to increase as a consequence of the heat addition process. It is mainly the velocity in conjunction with a critical annulus clearance that determines the magnitude of the convective heat transfer coefficient. In fact, if the vapor is considered steady or slowly moving inside the annulus, the heat transfer coefficient would be very low. This situation would be equivalent to a point in the Nukiyama curve beyond the critical heat flux (CHF) for which the corresponding heat fluxes are much lower because heat is transferred rather poorly across the vapor. It is also important to note that these processes occur in each cycle of the NPSEE and their overall duration is about 50 milliseconds when the crankshaft revolves at $\mathrm{RpM}=227$. In addition, the pressure rises in the annulus while the system volume changes continuously due to the motion of the piston.

Here, the relationship between the pressure and volume is assumed to be polytropic with the polytropic exponential derived from experimental data as described in Chapter 2.

To summarize, the heat cavities utilized in the NPSEE are represented by a series of concentric tubes hydraulically connected to the injector chamber and vented on one side to the expansion chamber. As is shown in Fig. 5.9, a series of such cavities can be included in the design of the engine head.

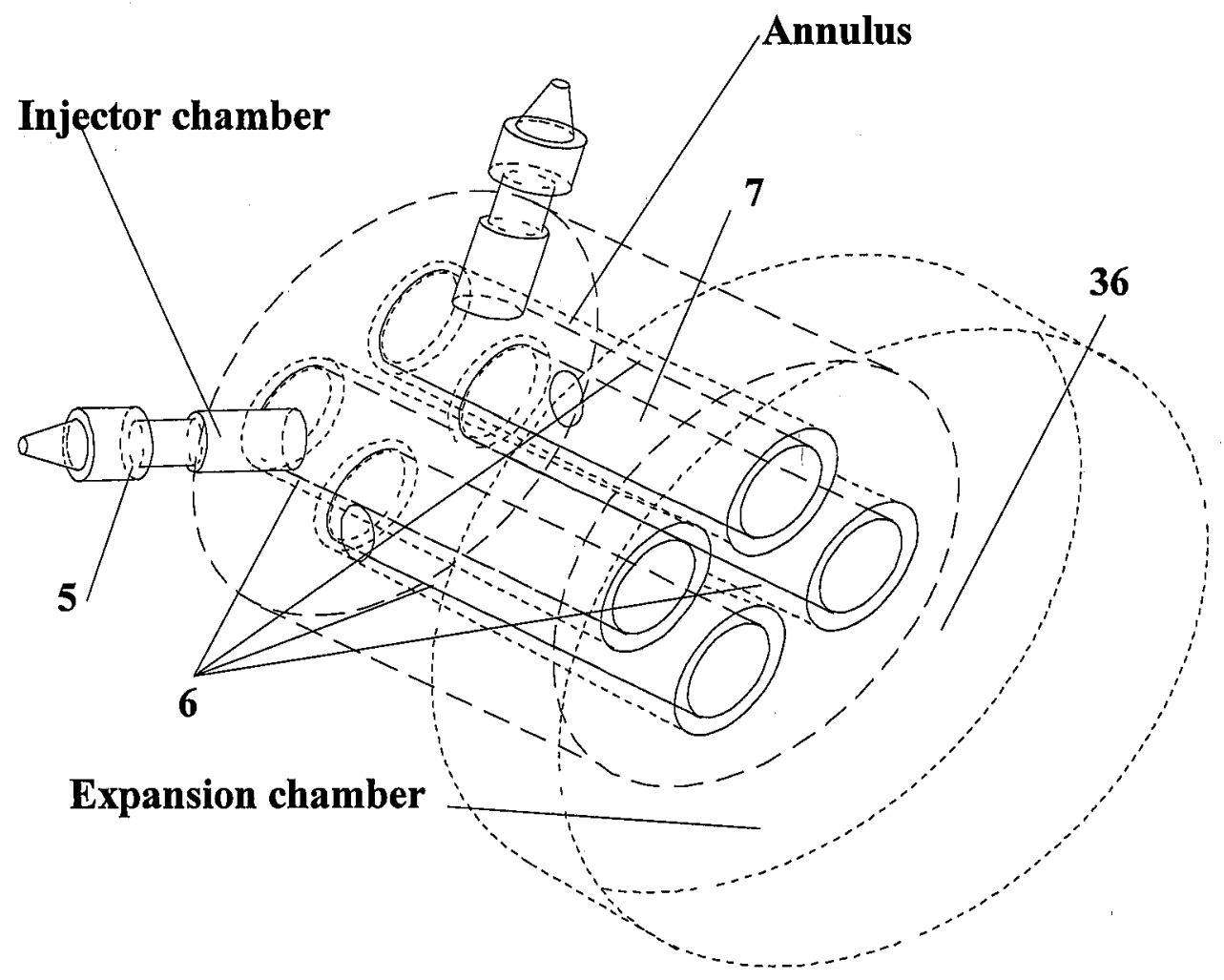

Figure 5.9: NPSEE heat cavities and injectors structure 
The clearance of the annulus formed between the heaters surfaces (fuel rods) and the surrounding walls determines the rate of heat transfer from the cladding surface to the injected fluid. In order to estimate the heat transfer parameters it is necessary to evaluate the velocity of the steam exiting the cavity as a result of the rapid expansion.

Consider the heat cavity as a thermodynamic system having one inlet and one exit for which the physical dimensions are known and the amount of heat added during the expansion process is provided by the thermodynamic analysis described in Chapter 2. Such a thermodynamic system can be represented by the nozzle shown in Fig. 5.10.

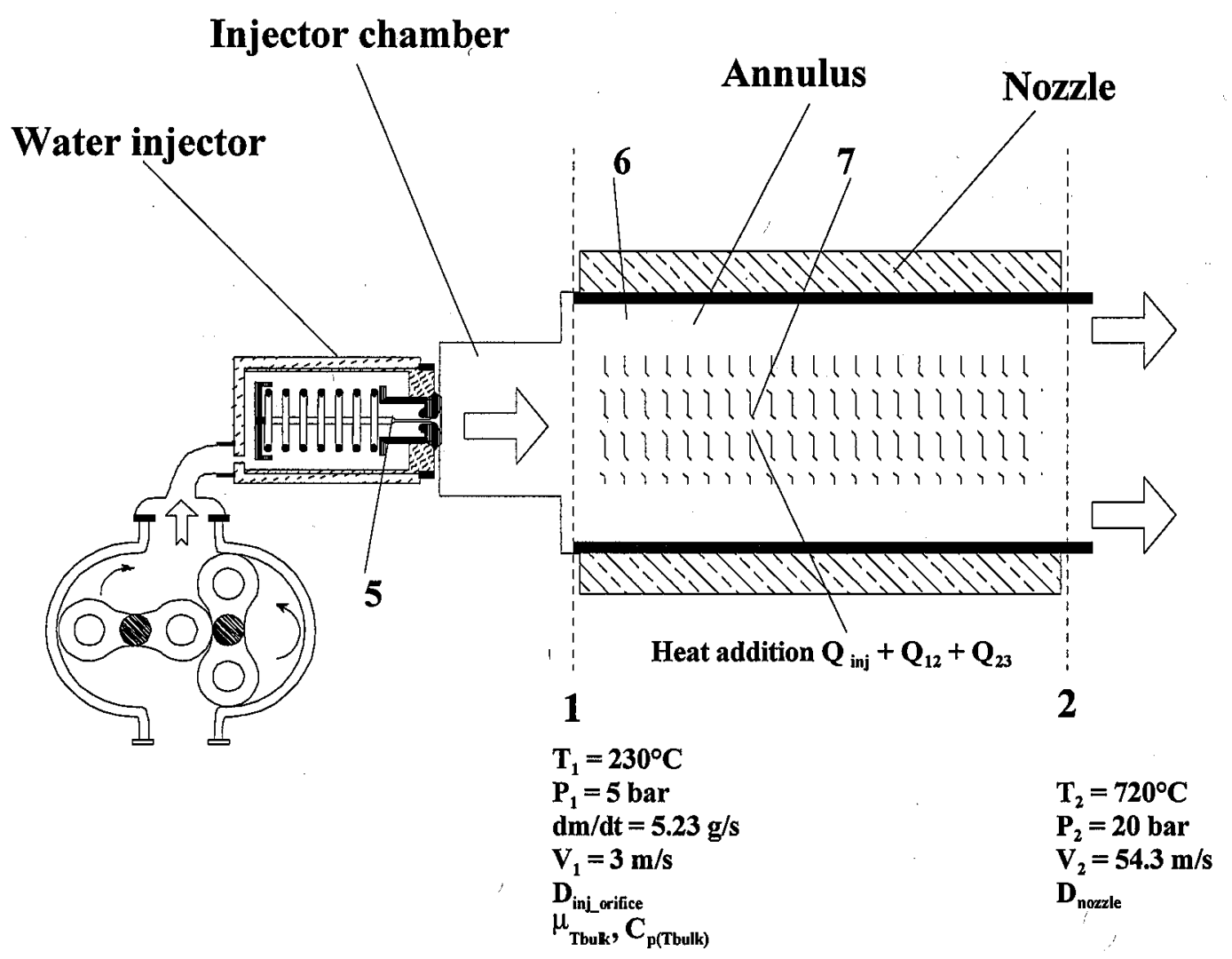

Figure 5.10: Nozzle analogue

As is shown in Fig. 5.10, the injected coolant enters the nozzle boundary at the inlet [1]. The inlet thermodynamic state is known and the inlet velocity is assumed to be the velocity of the coolant exiting the injector orifice. The in-depth description of the injector parameters is provided in section 2.3. As shown in Eq. 2.13, the velocity at the injector orifice is about $3 \mathrm{~m} / \mathrm{s}$. The outlet pressure and temperature are known and the equivalent cross sectional area of the annulus at the nozzle exit (2) is also known. To simplify the analysis, the RpM is set to 227 and the fluid properties are computed at an average inlet-outlet temperature denoted by $\mathrm{T}_{\text {bulk. }}$.

For internal flow problems, a mean temperature denoted by $T_{m}$ is utilized. This approach requires knowledge of the temperature and velocity profile in the annulus. 
However, the optimized annulus clearance, experimentally determined, resulted in about $0.00015 \mathrm{~m}(150 \mu \mathrm{m})$, while the boundary layer thickness (evaluated in Appendix $\mathrm{V})$, denoted by the symbol $\delta$, resulted in $55 \mu \mathrm{m}$ at a distance $\mathrm{X}_{\mathrm{fd}}$ of about $3.7 \mathrm{~mm}$ from the injector chamber. This implies that at about $15 \%$ of the overall annulus length, the two boundary layer thicknesses developing, one on the heater surface and the other on the surrounding tube wall, touch one another, thereby defining the hydrodynamic entrance region (consider that the cross section of the annulus is similar to two walls separated by a gap of $150 \mu \mathrm{m}$ ). In reality, the hydrodynamic entry length is even smaller because the heat transfer mechanism is characterized by turbulence already beginning in the injector chamber. For turbulent flow there is no satisfactory general expression for the entry length. It is known that $\mathrm{X}_{\mathrm{fd}}$ is approximately independent of the Reynolds number, and as a first approximation Eq. 5.11 is usually used.

$$
10 \leq\left.\frac{-X_{\text {fd }}}{D}\right|_{\text {Turbulent }} V_{\rfloor} \leq 60
$$

In this case, the fully developed entrance length would result in $\mathrm{X}_{\mathrm{fd}}<0.003 \mathrm{~m}$, and fully developed conditions could be assumed to occur at about $12 \%$ of the total annulus length.

The convective heat transfer coefficient in the cavity can be estimated by using Newton's law of cooling or by using correlations. Correlations available for twophase, turbulent flow in concentric tubes do not yield good accuracy when the ratio $D_{i} / D_{0} \approx 1$, where $D_{i}$ is the inner tube diameter, and $D_{0}$ is the diameter of the wall surrounding the cavity (recall that the annulus gap is only $150 \mu \mathrm{m}$ ).

The results of the computation, obtained by using an average temperature of $475^{\circ} \mathrm{C}$ and a Reynolds number of 114,460 , are shown in Tab. 5.2. The Reynolds number was estimated by assuming a velocity of about $54 \mathrm{~m} / \mathrm{s}$ (this is the velocity computed in Eq. 5.13).

\begin{tabular}{|c|c|c|c|c|}
\hline $\begin{array}{c}\mathrm{T}_{\text {avg }} \\
\left(\mathrm{T}_{\text {in }}-\mathrm{T}_{\text {out }}\right) / 2\end{array}$ & $\begin{array}{c}\text { Critical distance } \\
\left(\mathrm{X}_{\mathrm{c}}\right)\end{array}$ & $\begin{array}{c}\text { Heater length } \\
\text { (Glow plug) }\end{array}$ & $\begin{array}{c}\mathrm{h} \text { - from Ch.2 data } \\
\text { (Newton's law) }\end{array}$ & h- Correlation \\
\hline${ }^{\circ} \mathrm{C}$ & $(\mathrm{m})$ & $(\mathrm{m})$ & $\mathrm{W} / \mathrm{m}^{2}-\mathrm{K}$ & $\mathrm{W} / \mathrm{m}^{2}-\mathrm{K}$ \\
\hline 475 & 0.0037 & 0.025 & 7,417 & 5,200 \\
\hline
\end{tabular}

\section{Table 5.2: Cavity heat transfer coefficients}

Therefore, since the annulus clearance is smaller than the boundary layer thickness itself (for the velocity and fluid properties considered), the temperature profile can be assumed constant along the radial direction.

To summarize, the characteristics of the expanding vapor in the annulus are such that fully developed flow characteristics can reasonably be assumed to occur right after the injector chamber.

Going back to the nozzle analogue of the heat cavity, Eq. 2.1 is utilized for the computation of the steam velocity at the exit (2). The problem at hand is a time dependent problem; however, by considering the inlet-outlet conditions and the heat addition $\mathrm{Q}_{\mathrm{inj}}, \mathrm{Q}_{12}$ and $\mathrm{Q}_{23}$ as occurring at steady-state, an estimate of the magnitude of 
the steam velocity can be determined (this is equivalent to "taking a picture" of the 50 millisecond process and analyzing it as if it were at steady-state). Since the work rate term in the energy balance equation is zero, the velocity can be derived from a simplified version of Eq.2.1 as shown in Eq. 5.13:

$$
\frac{\stackrel{?}{\mathrm{Q}}}{\stackrel{?}{m}}=\mathrm{h}_{2}-\mathrm{h}_{1}+\frac{V_{2}^{2}}{2}-\frac{V_{1}^{2}}{2}
$$

$$
V_{2}=\sqrt{\frac{\stackrel{?}{\mathrm{Q}_{\text {tot }}}}{\frac{?}{m}}+\mathrm{h}_{1}-\mathrm{h}_{2}+\frac{V_{1}^{2}}{2} ? \frac{1}{1000} \sqrt{ } ? 2} ? \frac{m}{\mathrm{~s}}
$$

where

$$
\begin{array}{ll}
\mathrm{h}_{1}=\text { inlet enthalpy } & {[\mathrm{kJ} / \mathrm{kg}]} \\
\mathrm{h}_{2}=\text { outlet enthalpy } & {[\mathrm{kJ} / \mathrm{kg}]} \\
\mathrm{Q}_{\text {tot }}=\mathrm{Q}_{\text {inj }}+\mathrm{Q}_{12}+\mathrm{Q}_{23} & {[\mathrm{~kJ} / \mathrm{kg}]}
\end{array}
$$

The theoretical steam exiting velocity, denoted by $V_{2}$, increased to the value of $V_{2}=54.3 \mathrm{~m} / \mathrm{s}$ from the inlet value of $V_{1}=3 \mathrm{~m} / \mathrm{s}$ as a consequence of the heat transferred to the coolant while it passed through the heat cavity.

\subsection{Temperature Transient Across Cladding Material}

The power along the fuel rods utilized in the heat cavities changes as a function of the reactivity oscillation. The time dependent reactor power behavior is dictated by the neutron flux derived in Eq. 4.16 (described in the kinetic analysis in Chapter 4). When the crankshaft of the NPSEE is revolving at $227 \mathrm{RpM}$, the period of the power oscillation is in the order of hundreds of milliseconds.

The lumped capacitance method is utilized to estimate the temperature variation on the cladding surfaces caused by the power oscillation. The cladding surface temperature is dependent on the heat generation rate occurring in the fuel rod and on the coolant flowing in the annulus. However, due to the thermal inertia characterized by the thermal conductivity and specific heat of the cladding material, the induced temperature oscillation might be damped out and result in a steady surface temperature. The power changes in a periodic non-harmonic fashion with a period of about 132 milliseconds (this variable is denoted by "tcrank" in the thermodynamic analysis). Then, at the corresponding frequency the cladding material might not be able to follow the induced temperature variation and behaves as a large electric capacitor. In this case, the temperature reached on the surface of the cladding would result in an averaged time independent value. For example, consider the temperature of the tungsten of a light bulb and imagine switching it on and off every 132 milliseconds (equivalent to turning it on and off at a corresponding frequency of about $7.7 \mathrm{~Hz}$ ). Due to the thermal inertia of the tungsten material the overall temperature would reach a steady averaged value even though the power is periodically changing. A similar behavior is expected to occur in the cladding material encasing the fuel rod. 
Therefore, before proceeding to the estimate of the heat transfer parameters involved in the annulus of the heat cavity, it is necessary to evaluate numerically whether the cladding surface temperature changes as a consequence of the periodic power generated in the fuel rod.

For this estimate, consider a $0.0015 \mathrm{~m}$ thick zircaloy cladding material and assume that the initial cladding temperature was fixed at an average value determined by the parameters obtained in the thermodynamic analysis in Chapter 2 . Then, assume that the temperature on the inner side of the zircaloy tube was suddenly changed. As a consequence, the temperature change propagates across the clad thickness and eventually it will reach an equilibrium. By applying the lumped capacitance method, the estimated time for the transient to dissipate is approximately 1.482 seconds (recall that the period of the power oscillation is only 132 millisecond at the given RpM, see Appendix V). The Biot number, for the given conditions, is about 0.073 , implying that the application of the lumped capacitance method is justified. The Biot number, denoted by $\mathrm{Bi}$, is given by Eq. 5.14 , and the lumped capacitance method yields a reasonable accuracy if $\mathrm{Bi}<0.1$.

$$
\mathrm{Bi}=\frac{\mathrm{h} ? \mathrm{Lc}}{\mathrm{K}}<0.1
$$

In conclusion, the cladding surface temperature can be assumed to be independent of the power oscillation. This assumption is valid as long as the power oscillates with a period determined by a relatively high number of RpM, and does not . increase as time elapses as shown in Fig. 4.11. The cladding surface temperature is also subjected to the heat transferred to the coolant flowing into the annulus. The coolant bulk temperature is expected to increase along the annulus, as well as the cladding surface temperature. There will be a location along the annulus for which the cladding temperature shows a maximum value. Since the maximum cladding temperature cannot exceed the design value of $720^{\circ} \mathrm{C}$ (maximum temperature for which $\eta_{\text {cycle }}=56.2 \%$ ) it is important to establish the axial location in the annulus for which the cladding temperature is at its maximum. This and other parameters will now be evaluated.

\subsection{Axial Variation of Local Heat Flux Along the Annulus}

In order to estimate the heat transfer parameters involved in the annulus it is necessary to make a series of simplifications. With reference to Fig. 5.11, the annulus forming the heat cavity is considered to begin right after the injector chamber. 


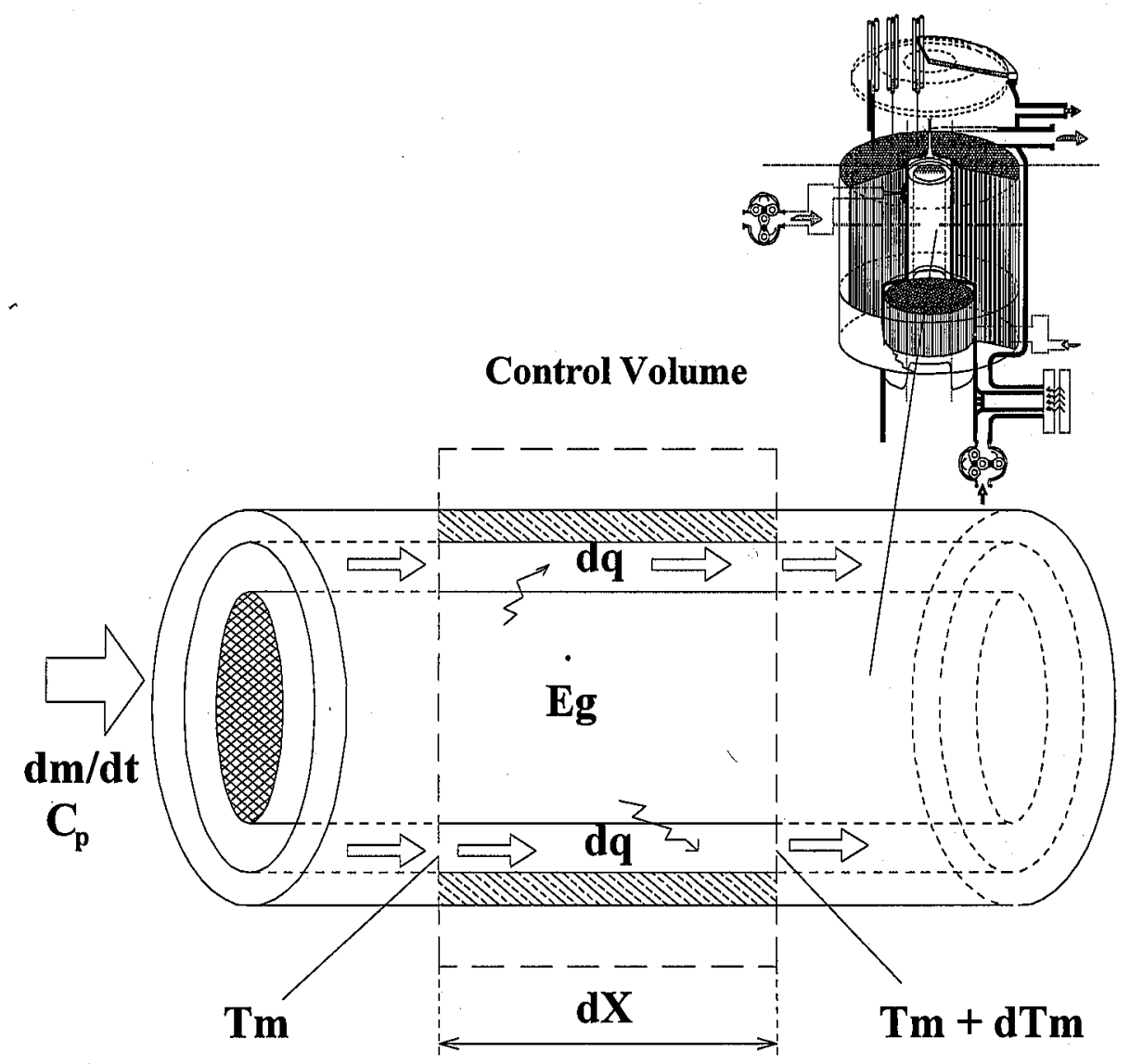

Figure 5.11: Heat cavity, internal flow

As described in the previous paragraphs, the thermodynamic state of the coolant changes continuously while it passes through the annulus. However, the steam quality is already $54.2 \%$ as a result of the opening of the injector valve (see Appendix II), and it becomes superheated when it starts to enter the annulus region. Therefore, the coolant can be considered a single-phase superheated vapor entering the annulus with a known mass flow rate. The coolant properties can be first evaluated at an average temperature between the annulus inlet and outlet conditions, then they can be iterated until convergence is obtained.

Heat generation occurs within the fuel rod according to Eq. 5.10 in which the $\mathrm{J}_{0}$ Bessel's function is needed to describe the shape of the core power distribution along the radial direction. However, by considering only one fuel rod and assuming that the volumetric heat generation rate varies sinusoidally with distance along the annulus (zdirection in Eq.5.10), the analysis is greatly simplified (the more complicated alternative is that of using the non-harmonic function).

The heat transfer coefficient can be estimated by using correlations or derived from knowledge of the heat addition rates, namely $\mathrm{Q}_{\mathrm{inj}}, \mathrm{Q}_{12}$ and $\mathrm{Q}_{23}$, in conjunction with the surface and bulk coolant temperatures. A uniform heat convection coefficient is assumed to exist between the cladding surfaces and the superheated vapor flowing 
through the annulus. To further simplify the analysis, only one cycle of the NPSEE at $\mathrm{RpM}=227$ is considered, and all of the parameters involved are assumed to be at steady-state conditions (again, this is equivalent to "taking a picture" of the expansion process a few milliseconds after the vapor has entered the annulus and analyzing the parameters as if they were at steady-state).

Therefore, by performing an energy balance for the control volume shown in Fig. 511, and including in the control volume boundaries the fuel rod only, the energy balance reduces to:

$$
\stackrel{?}{\mathrm{E}}_{\text {generated }}=\stackrel{?}{\mathrm{E}}_{\text {out }}
$$

where:

$$
\begin{aligned}
& \stackrel{?}{\mathrm{E}}_{\text {generated }}=\mathrm{C}_{0} ? \sin \frac{\pi ? \mathrm{x}}{\mathrm{L}} \sqrt{ } ? \frac{\pi \mathrm{D}^{2}}{4} \mathrm{~J} \\
& \stackrel{?}{\mathrm{E}}_{\text {out }}=\mathrm{q}^{\prime \prime}(\pi ? \mathrm{D}) \\
& \mathrm{C}_{0}=\text { constant } \stackrel{?}{\mathrm{q}}_{0} \text {, and } 0 \leq \mathrm{x} \leq \mathrm{L}
\end{aligned}
$$

Then, by solving for q" in Eq. 5.15, the axial variation of the local heat flux is derived as shown in Eq. 5.16.

$$
\mathrm{q}^{\prime \prime}=\mathrm{C}_{0} ? \frac{\mathrm{D}}{4} \sqrt{ } \mathrm{J} \cdot \sin \frac{\pi ? x}{\mathrm{~L}} \sqrt{ }
$$

In order to evaluate the total heat transfer rate it is enough to integrate Eq. 5.16 over the length of the fuel rod (the length of the fuel rod is assumed to be $0.025 \mathrm{~m}$ which is the actual length of the heaters utilized in the NPSEE analogue).

$$
\mathrm{q}=\mathrm{q}_{0}^{\mathrm{L}} \mathrm{q}(\pi ? \mathrm{D}) ? d x=\frac{\mathrm{D}^{2} ? \mathrm{~L}}{2} ? \mathrm{C}_{0}
$$

By substituting the numerical values of the constants in Eq. 5.17, the estimate of the total heat transfer can be obtained. The numerical value for the volumetric heat flux $\mathrm{C}_{0}$, can be obtained by summing the contributions of $\mathrm{Q}_{\mathrm{inj}}, \mathrm{Q}_{12}$ and $\mathrm{Q}_{23}$ determined in the thermodynamic analysis.

\subsection{Axial Variation of the Average Coolant Temperature}

With reference to Fig. 5.11, the energy balance is now performed by including the coolant inside the control volume boundaries. By considering the specific heat $C_{p}$ constant, the energy balance is derived in Eq. 5.19. If a higher accuracy is required, a temperature dependent specific heat varying according to the Virial coefficients should be utilized.

$$
\stackrel{?}{\mathrm{~m}} ? \mathrm{C}_{\mathrm{p}} ? \mathrm{~T}_{\mathrm{m}}+\mathrm{dq}-\stackrel{?}{\mathrm{~m}} ? \mathrm{C}_{\mathrm{p}} ?\left(\mathrm{~T}_{\mathrm{m}}+\mathrm{dT} \mathrm{m}\right)=0
$$


where

$$
\mathrm{dq}=(\pi ? \mathrm{D} ? \mathrm{~d} x) ? \mathrm{q}^{\prime \prime}=\stackrel{?}{\mathrm{~m}} ? \mathrm{C}_{\mathrm{p}} ? \mathrm{dT}_{\mathrm{m}}
$$

By substituting dq back into Eq. 5.19 the following differential equation is obtained.

$$
\frac{\mathrm{dT}_{\mathrm{m}}(x)}{\mathrm{d} x}=\frac{\pi ? \mathrm{D}}{\frac{?}{\mathrm{~m} ? \mathrm{C}_{\mathrm{p}}}} ? \frac{\mathrm{C}_{0} \mathrm{D}}{4} ? \sin \frac{\pi}{\mathrm{L}} \stackrel{\mathrm{H}}{\mathrm{V}}
$$

where the boundary condition is: $\mathrm{T}_{\mathrm{m}}(\mathrm{x})=\mathrm{T}_{\mathrm{m}}(0)$ at the annulus inlet.

Finally, by integrating Eq. 5.20 the expression for the variation of the mean coolant temperature along the annulus can be derived.

$$
\mathrm{T}_{\mathrm{m}}(x)=\frac{\mathrm{L} ? \mathrm{D}^{2}}{4} ? \frac{\mathrm{C}_{0}}{\mathrm{mC}_{\mathrm{p}}} ? \overline{1}-\cos \frac{\pi ? x}{\mathrm{~L}} \underset{ل}{\mathrm{~J}}+\mathrm{T}_{\mathrm{m}}(0)
$$

\subsection{Axial Variation of the Cladding Surface Temperature}

As the vapor passes through the annulus, heat is transferred from the cladding surface to the coolant. The temperature of the vapor and the temperature at the cladding surface changes as the vapor moves toward the exit of the cavity. Therefore, by utilizing Newton's law of cooling Eq. 5.1, a general expression for the surface temperature denoted by $\mathrm{T}_{\mathrm{s}}$ can be obtained as shown in Eq. 5.22.

$$
\mathrm{T}_{\mathrm{s}}=\frac{\mathrm{q}^{\prime \prime}}{\mathrm{h}}+\mathrm{T}_{\mathrm{m}}(x)
$$

By substituting the expression for the mean coolant temperature obtained in Eq.5.21 into Eq. 5.22, the variation of the temperature cladding surface can be derived.

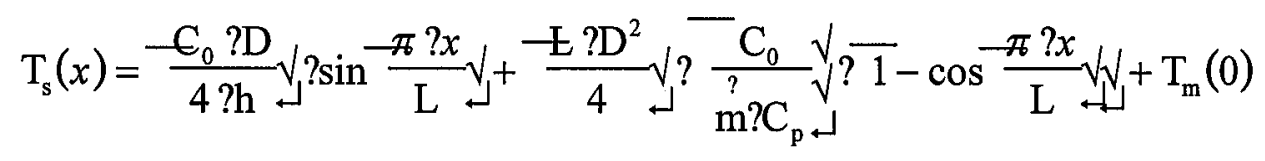

Finally, by differentiating Eq. 5.23 and setting it to zero, the location at which the temperature reaches its maximum along the cladding surface can be estimated. In this case, when $\mathrm{dT}_{\mathrm{s}(\mathrm{x})} / \mathrm{dx}=0$ the expression for $\mathrm{x}_{\max }$ becomes:

$$
\frac{\mathrm{C}_{0} ? \pi ? \mathrm{D}}{4 ? \mathrm{~h} ? \mathrm{~L}} \sqrt{ } ? \cos \frac{\pi ? \mathrm{x}_{\max }}{\mathrm{L}}+\frac{\mathrm{D}^{2} ? \pi ? \mathrm{C}_{0}}{4 ? \mathrm{~m} ? \mathrm{C}_{\mathrm{p}}} ? \sin \frac{\pi ? \mathrm{x}_{\max }}{\mathrm{L}}=0
$$




$$
\mathrm{x}_{\max }=\frac{\mathrm{L}}{\pi} ? \arctan \frac{\stackrel{\mathrm{m}}{\mathrm{m}} \mathrm{C}_{\mathrm{p}}}{\mathrm{D} ? \mathrm{~h} ? \mathrm{~L}} \sqrt{ }
$$

Then, by substituting the numerical values into Eq. 5.25 , the location at which the theoretical maximum coolant temperature occurs is $\mathrm{x}_{\max }=0.025 \mathrm{~m}$ (see Appendix $\mathrm{V})$. In other words, immediately after the injection the coolant is relatively cold $\left(T_{\text {in }}=230^{\circ} \mathrm{C}\right)$, then as it enters the annulus its temperature increases $\left(T_{\text {out }}=720^{\circ} \mathrm{C}\right)$. At the end of the annulus (where $\mathrm{L}=0.025 \mathrm{~m}$ ), assuming a sufficiently high heat transfer coefficient, and considering that the clearance through which the fluid passes is only $150 \mu \mathrm{m}$, the temperature of the exiting steam and that of the cladding surface are almost the same. As the vapor approaches the exit of the cavity, its cooling potential is reduced and the temperature difference between the vapor and the cladding decreases. Then, the highest surface temperature is expected to occur toward the end of the annulus; therefore, the approximated value of $x_{\max }=0.025 \mathrm{~m}$ confirms the expectation.

This aspect is further validated when the problem is considered from a thermodynamic point of view. Consider that the ratio of the volume of the heater to the total volume occupied by the water injected is $V_{\text {heater }} / V_{\text {coolant }} \approx 10$. Due to the thermal inertia of the heater material and to the very short injection phase (tInject $=0.011$ seconds at $\mathrm{RpM}=227$ ) the heater temperature does not change significantly while the temperature of the coolant changes from $230^{\circ} \mathrm{C}$ to $720^{\circ} \mathrm{C}$. In other words, the heater is a much larger thermodynamic system and its internal energy does not vary significantly compared to the system represented by the mass of coolant.

In conclusion, the temperature of the coolant increases along the axial direction according to Eq. 5.23. The mean coolant temperature is assumed to be $230^{\circ} \mathrm{C}$ at the inlet of the annulus $\left(\mathrm{T}_{\mathrm{m}(0)}\right)$ while the maximum coolant temperature is achieved at the end of the annulus for which $\mathrm{T}_{\mathrm{m}(\mathrm{L})}=720^{\circ} \mathrm{C}$ as required in the thermodynamic analysis described in Chapter 2.

\subsection{Annulus Radiative Heat Effects}

Since the cladding surface temperature is high $\left(\mathrm{T}_{\text {clad }} \approx 993 \mathrm{~K}\right)$, it is necessary to estimate the magnitude of the heat transferred through the vapor by radiation. This is the case in which the emissivity of the cladding material and that of the surrounding wall, denoted by $\varepsilon_{\text {clad }}$ and $\varepsilon_{\text {wall }}$ respectively, might impact the overall characteristics of the coolant expansion processes occurring in the heat cavity. In order to evaluate the magnitude of the heat radiated from the fuel rod (heater), several radiation heat transfer correlations can be used. However, with the purpose of simplifying this analysis a series of assumptions have to be made.

Consider the annulus represented in Fig. 5.12 where two concentric tubes represent the analogue of the heat cavity.

The first assumption is that of considering the coolant in a superheated state at an average temperature of about $475^{\circ} \mathrm{C}$ (this variable is denoted by T_bulk in the relative program reported in Appendix V), and a pressure of 5 bars, corresponding to the NPSEE cycle initial pressure denoted by $P_{1}$. The coolant is assumed quiescent 
and the only heat transfer mechanisms taking place in the annulus region are those of free convection and radiation.

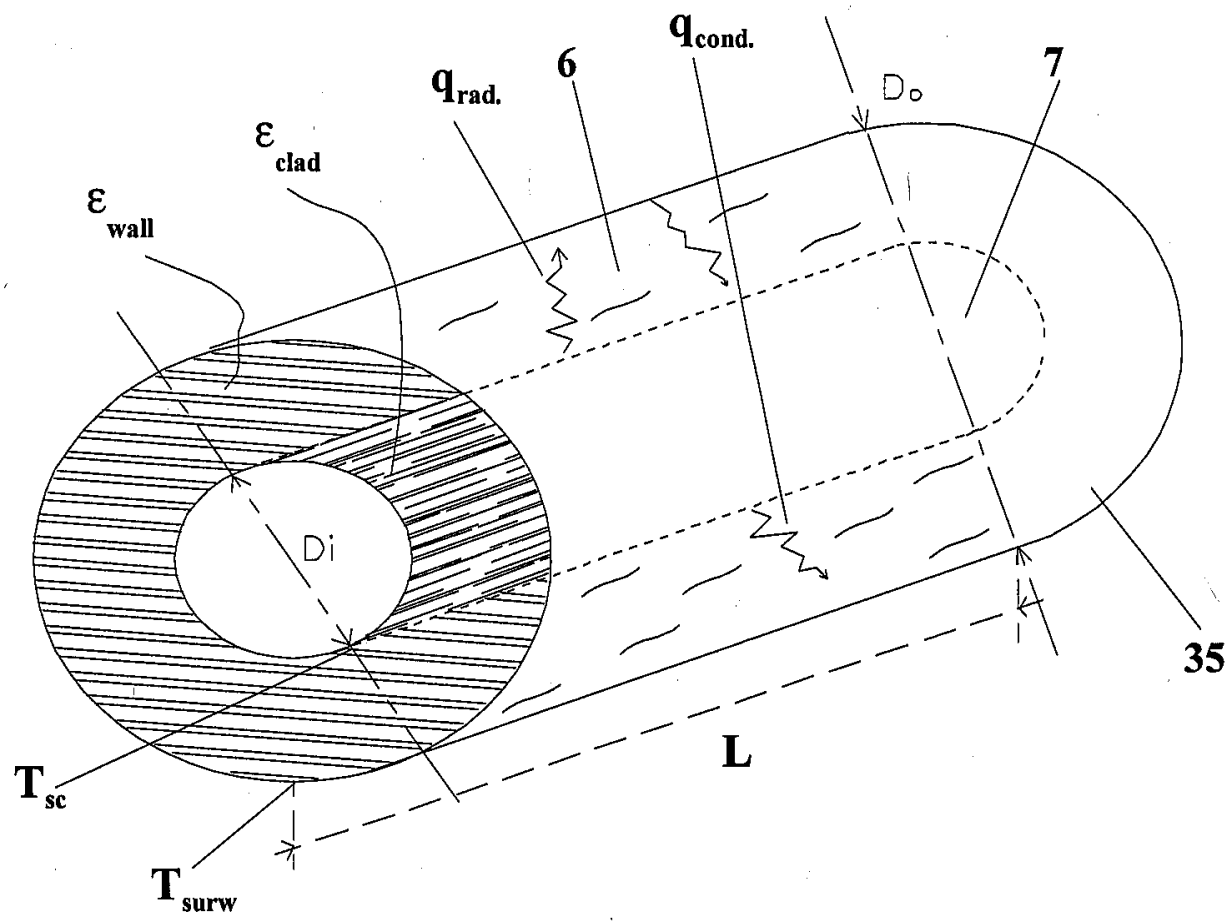

Figure 5.12: Radiative heat loss

The values of the clad-wall emissivity utilized in the computation are those of aluminum since this is the material utilized in the actual NPSEE heat cavity analogue. Therefore, an energy balance performed on the annulus reduces to:

where

$$
\begin{gathered}
\mathrm{q}_{\text {tot }}=\mathrm{q}_{\text {rad. }}+\mathrm{q}_{\text {conv }} \quad(5.26) \\
\mathrm{q}_{\text {rad. }}=\frac{\sigma ?\left(\pi ? \mathrm{D}_{\text {in }} ? \mathrm{~L}\right) ?\left(\mathrm{~T}_{\mathrm{sc}}^{4}-\mathrm{T}_{\text {surw }}^{4}\right)}{\frac{1}{\varepsilon_{\mathrm{c}}}+\frac{1-\varepsilon_{w}}{\varepsilon_{w}} ? \frac{r_{\text {in }}}{r_{\text {out }}}} \\
\sigma=\text { Stefan-Boltzmann constant } \\
\varepsilon_{\mathrm{c}}=\text { cladding emissivity } \\
\varepsilon_{\mathrm{w}}=\text { wall emissivity }
\end{gathered}
$$

In order to estimate the convective heat transfer, $\mathrm{q}_{\mathrm{conv}}$ in Eq. 5.26, the Rayleigh number is evaluated according to Eq. 5.27 and compared with the correlation developed by Kuehn and Goldstein which accounts for convective flow in concentric cylinders as described in Eq. 5.28.

$$
\mathrm{Ra}_{\mathrm{L}}=\frac{\mathrm{g} ? \beta ?\left(\mathrm{~T}_{\mathrm{sc}}-\mathrm{T}_{\text {surw }}\right) ? \mathrm{~L}^{3}}{\alpha ? v}
$$




$$
\mathrm{Ra}_{\text {Cylinder }}^{*}=\frac{\ln \frac{\bigoplus_{\text {out }}}{\mathrm{D}_{\text {in }}} ل^{4}}{\mathrm{~L}^{3} ?\left(\mathrm{D}_{\text {in }}^{-0.6}+\mathrm{D}_{\text {out }}^{-0.6}\right)^{5}} ? \mathrm{Ra}_{\mathrm{L}}
$$

By substituting the numerical values into Eq. 5.27 and Eq. 5.28, $\mathrm{Ra}_{\mathrm{L}}=12786$ and $\mathrm{Ra}^{*}{ }_{\text {Cyl. }} \approx 10^{-6}$. Since $\mathrm{Ra}^{*}{ }_{\mathrm{Cyl}}$ is almost zero, the implication is that the main mechanism of heat transfer through the vapor blanket is that of conduction, and the free convection effects are negligible. Then, Eq. 5.26 can be rewritten as:

where

$$
\begin{aligned}
\mathrm{q}_{\text {tot }} & =\mathrm{q}_{\text {rad. }}+\mathrm{q}_{\text {cond. }} \\
\mathrm{q}_{\text {cond. }} & =\frac{2 \pi \text { ? } ? \mathrm{~K}_{\text {steam }} ?\left(\mathrm{~T}_{\text {sc }}-\mathrm{T}_{\text {surw }}\right)}{\left.\ln \frac{\boldsymbol{F}_{\text {out }}}{r_{\text {in }}}\right\rfloor}
\end{aligned}
$$

The results of this analysis show that only about $0.7 \%$ of the heat is transferred through the vapor as a result of radiation. The rest is transported through the vapor via conduction. Indeed, this might seem a very low value. But, it is enough to consider that the annulus clearance is only $0.00015 \mathrm{~m}(150 \mu \mathrm{m})$, and as the ratio of the inner diameter to the outer diameter becomes closer to unity, most correlations are not applicable or yield poor accuracy. However, it is also intuitive to predict that the temperature difference between the clad surface and the wall becomes more and more negligible as the inner radius approaches the radius of the surrounding wall. Therefore, the assumption of negligible radiative effects is justified for the given temperatures.

In conclusion, the analysis of the heat transfer mechanisms involved in the annulus region showed that the heat cavity behaves as a nozzle in which heat is transferred mainly as a result of convection and conduction. As a result of the coolant expansion inside the cavity the velocity at the exit of the cavity increases significantly. It is mainly the high velocity of the steam exiting the cavity, and the explosive nature of the expansion process itself which induces turbulent flow conditions. The estimated Reynold's number was about 114,459 in the annulus region and the approximate turbulent Reynolds number for internal flow is assumed to occur for $\mathrm{Re}>2300$. The estimated hydraulic entrance region was about $12 \%$ of the total annulus length. Finally, the radiation heat transfer effect has been evaluated and the results justify the assumption of negligible radiative effects made throughout the heat transfer analysis.

In general, due to the special characteristics of the heat cavities utilized in the NPSEE, and especially because of the very narrow gap between the cladding material and the surrounding wall, the correlations utilized might yield large errors. For these reasons, a more accurate evaluation of the parameters involved relies on experimental data. 


\section{Analogue Determination of Pi Terms}

With reference to the apparatus shown in Fig. 6.2, consider the following:

- By controlling the current through the heater, the heat rate can be measured and varied as desired.

- The volume V, characterizing the total volume formed by the heat cavity annulus and the expansion chamber, can be varied by changing the length and/or the diameter of the cylinder C. In this manner, by repeating the experiment with different volumes, the non-harmonic volume change can be reproduced.

- The total fluid mass injected can be varied by adjusting the position of the metering valve in the diesel pump and/or by changing the compressor speed. In this way, the duration of the injection can be set as desired.

- By fixing the injection pressure and measuring the temperature of the water prior to the injection phase, the enthalpy of the fluid can be determined and changed simply by changing the fluid temperature.

- By assuming quasi-steady conditions, considering only initial and final states, the time dependence can be ignored. However, as it will be shown, if time is considered, an additional Pi term is needed to describe the expansion process.

Then, as a first approximation, the pressure inside the cavity becomes a function of at least four parameters. The minimum number of variables required to describe the pressure change as a result of the expansion process are the heat rate, the enthalpy of the fluid, the system volume, and the mass flow rate, as is shown in Eq. 6.4.

$$
\mathrm{P}=\mathrm{f}(\stackrel{?}{\mathrm{Q}}, \mathrm{h}, \mathrm{V}, \stackrel{?}{\mathrm{~m}})
$$

Then, these five variables are defined in terms of basic dimensions: 


$$
\begin{aligned}
& \mathrm{P}=\frac{\mathrm{N}}{\mathrm{m}^{2}}=\mathrm{F} ? \mathrm{~L}^{-2} \\
& \mathrm{Q}=\frac{\mathrm{W}}{\mathrm{m}^{3}}=\mathrm{F} ? \mathrm{~L}^{-2} ? \mathrm{~T}^{-1} \\
& \mathrm{~h}=\frac{\mathrm{J}}{\mathrm{Kg}}=\mathrm{L}^{2} ? \mathrm{~T}^{-2} \\
& \mathrm{~V}=\mathrm{m}^{3}=\mathrm{L}^{3} \\
& ? \\
& \mathrm{~m}=-\frac{\mathrm{V} ? \mathrm{~A}}{\mathrm{v}}=\frac{\left(\mathrm{L} ? \mathrm{~T}^{-1}\right)\left(\mathrm{L}^{2}\right)}{\mathrm{L}^{3} ? \mathrm{M}^{-1}}=\mathrm{F} ? \mathrm{~L}^{-1} ? \mathrm{~T}
\end{aligned}
$$

At this point, by applying the Pi theorem, two Pi terms are required to describe the process. In particular, there are five variables, including the dependent variable $P$, and the minimum number of independent basic dimensions is three: force (F), length (L) and time (T). The evaluation of the exponential terms in the dimensionless group yields the final form of the two Pi terms required.

$$
\begin{aligned}
& \Pi_{1}=\frac{\mathrm{P} ?(\mathrm{~h})^{\frac{1}{2}}}{\mathrm{~V}^{\frac{1}{3}} ? \stackrel{\mathrm{Q}}{2}} \\
& \Pi_{2}=\frac{\stackrel{?}{\mathrm{~m} ? \mathrm{~h}}}{\mathrm{~V} ? \stackrel{\mathrm{Q}}{ }}
\end{aligned}
$$

Furthermore, the Pi terms are related according to a relationship of the form:

$$
\begin{gathered}
\Pi_{1}=\Phi\left(\Pi_{2}\right) \\
\frac{\mathrm{P} ? \sqrt{\mathrm{h}}}{\sqrt[3]{\mathrm{V}} ? \stackrel{?}{\mathrm{Q}}}=\Phi \frac{?}{\mathrm{~m} ? \mathrm{~h}} \sqrt{\mathrm{V} ? \mathrm{Q}}
\end{gathered}
$$

Therefore, the dependence of the pressure on the independent $\mid$ variables $\stackrel{?}{\mathrm{~m}}, \stackrel{?}{\mathrm{Q}}, \mathrm{h}$, and $\mathrm{T}$ is as indicated in Eq. 6.7. Furthermore, if the independent variable time, denoted by $\mathrm{t}$, is also 
included, then three Pi terms, $\Pi_{1}, \Pi_{1}$ and $\Pi_{3}$ are required and the pressure could be expressed as a function of five independent variables:

$$
P=f(\stackrel{?}{m}, h, \stackrel{?}{Q}, V, t)
$$

In this case, it is possible to express $\Pi_{1}$ as a function of $\Pi_{2}$ while keeping $\Pi_{3}$ constant. Overall, a series of curves describing the relationships between the parameters involved in the expansion process can be obtained. Finally, by using polynomial fitting techniques the final form of the correlation can be derived. 


\section{Appendix 6}

\section{Case 2.1a: Superheated Steam at the Valve Inlet}

The measure of the amount of thermodynamic irreversibility generated in a thermal system is generally defined in terms of the system entropy production and/or availability destruction. In the NPSEE thermal system, the rate of entropy production, and the flow availability, are estimated by assuming an adiabatic process for both cases $2.1 \mathrm{a}$ and $2.1 \mathrm{~b}$, negligible kinetic and potential effects, no displacement of the system boundaries, and no work effects in the balancing equations. As shown in Fig. 2.1a, the turbine admission valve of such a system is represented by an insulated throttling device. The inlet/outlet conditions are those applied to the actual NPSEE analogue. Therefore, as is shown in Fig. 2.1a, and in the relative P$v$ diagram, at the inlet of the valve the fluid state is characterized by superheated water vapor entering the valve at $19 \mathrm{bars}, 605^{\circ} \mathrm{C}$ and exiting at a pressure of 5 bars. The fluid expansion occurring between the inlet and the outlet of the valve can be considered a throttling process, and the environmental pressure and temperature are assumed to be 1 bar and $293 \mathrm{~K}$, respectively.

The fluid inlet state is specified by a pressure of about 19 bars and a temperature of $605^{\circ} \mathrm{C}$ for which the relative entropy value, obtained in the steam table, is $S_{1}=7.726 \mathrm{~kJ} / \mathrm{kg}-\mathrm{K}$.

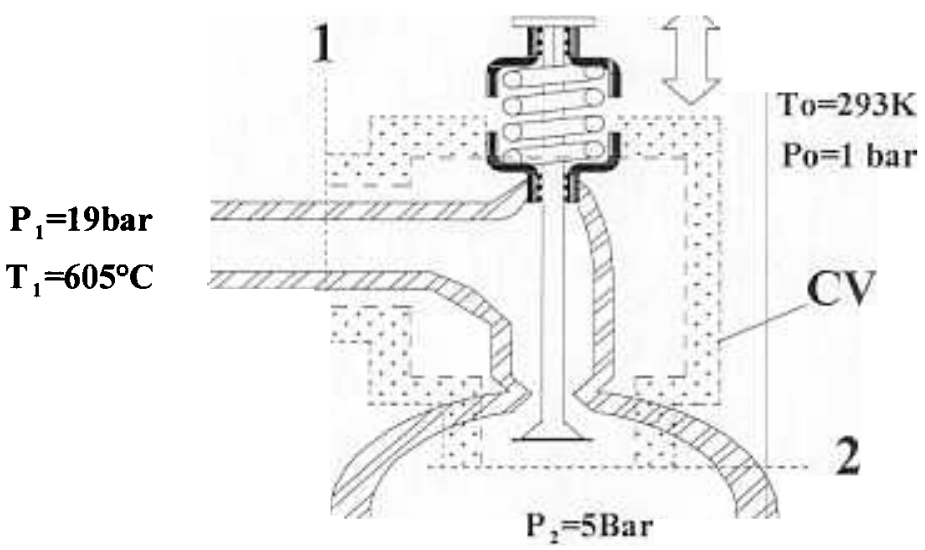

Figure 2.1a: Throttling device with super-heated steam at the inlet

The state at the exit can be fixed by reducing the steady-state mass and energy rate balance equations applied to the control volume represented by the insulated box surrounding the valve in Fig. 2.1a to obtain:

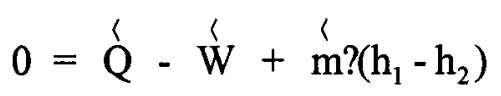

where under the assumptions stated before $\stackrel{\mathrm{Q}}{=} \mathrm{W}=0$, then

$$
\mathrm{h}_{2}=\mathrm{h}_{1}
$$

In this manner, the state at the exit is fixed by knowledge of $\mathrm{P}_{2}$ and $\mathrm{h}_{2}$. Here, the enthalpy of the initial state is set equal to the enthalpy of the final state (both states assumed to be equilibrium states) because the process is assumed to be isenthalpic, as shown in the h-s diagram for case 2.1a in the relative Fig. 2.1a. 
Therefore, the value of the inlet enthalpy at $P_{1}=19$ bar, $T_{1}=605^{\circ} \mathrm{C}$ is $h_{1}=h_{2}=3701.7$ $\mathrm{kJ} / \mathrm{kg}$. By interpolating at the outlet conditions, $\mathrm{P}_{2}=5$ bars, $\mathrm{h}=\mathrm{h}_{1}$, the temperature is determined, $\mathrm{T} 2=600^{\circ} \mathrm{C}$. Similarly, the specific volume $\mathrm{v}_{2}$ can now be fixed, $\mathrm{v}_{2}=0.8041 \mathrm{~m} 3 / \mathrm{kg}$, and the entropy at the valve exit is $S_{2}=8.3522 \mathrm{~kJ} / \mathrm{kg}-\mathrm{K}$.

Because of the adiabatic process assumption, the steady-state entropy rate balance equation, Eq. 2.3, reduces to

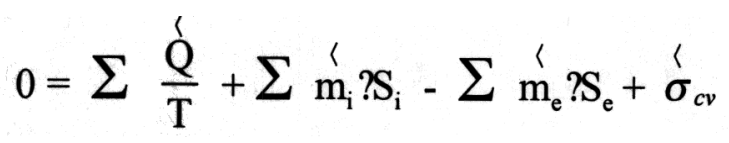

then, the entropy production rate takes the form

$$
\frac{\sigma_{\text {Steam }}}{\grave{m}}=\mathrm{S}_{2}-\mathrm{S}_{1}=0.6262 \mathrm{~kJ} / \mathrm{kg}
$$

In the absence of heat transfer and work terms the irreversibility rate reduces to

$$
\underset{\mathrm{m}}{\stackrel{\mathrm{I}}{\mathrm{T}}}=\mathrm{T}_{0} ? \underset{\mathrm{m}}{\stackrel{\vec{\sigma}}{\mathrm{T}} \mathrm{V}}=\mathrm{T}_{0}\left(\mathrm{~S}_{2}-\mathrm{S}_{1}\right)
$$

and for case 2.1a

$$
\frac{I_{\text {St. }}^{l}}{\grave{m}}=T_{0}\left(S_{2}-S_{1}\right)=183.5 \mathrm{~kJ} / \mathrm{kg}
$$

To summarize, the irreversibility production term for case $2.1 \mathrm{a}$ has an estimated value of $183.5 \mathrm{~kJ} / \mathrm{kg}$. In terms of flow availability, dropping the potential and kinetic energy terms, gz, and $\mathrm{V}^{2} / 2$ respectively, the specific flow availability is given by Eq. 2.5 , where $T_{0}$ and $h_{0}$ correspond to the environment conditions specified before, $\mathrm{T}_{0}=293 \mathrm{~K}, \mathrm{P}_{0}=1 \mathrm{bar}$. The flow availability is denoted by the symbol $\mathrm{a}_{\mathrm{f}}$.

$$
\mathrm{a}_{\mathrm{f}}=\mathrm{h}-\mathrm{h}_{0}-\mathrm{T}_{0} \text { ? }\left(\mathrm{S}-\mathrm{S}_{0}\right)
$$

With the assumptions listed, the steady-state form of the availability rate balance, Eq. 2.6, takes the form

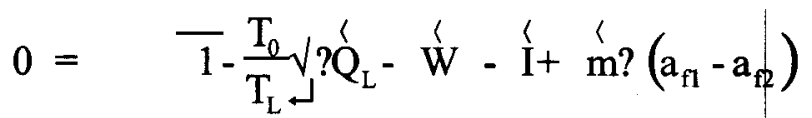

where the subscript $\mathrm{L}$ denotes local conditions.

Dividing by the mass flow rate and solving for the irreversibility rate derived from Eq. 2.6 the general form of the irreversibility rate is reduced to:

$$
\frac{\stackrel{I}{T}}{m}=\left(a_{f 1}-a_{f 2}\right)
$$

Since $h_{2}=h_{1}$, the expression for the irreversibility developed in the solution reduces to:

$$
\left(\mathrm{a}_{\mathrm{f} 1}-\mathrm{a}_{\mathrm{f}}\right)=\mathrm{T}_{0}\left(\mathrm{~S}-\mathrm{S}_{0}\right)=183.5 \mathrm{~kJ} / \mathrm{kg}
$$

Therefore, under the conditions listed for case 2.1a, the flow availability difference is equal to the irreversibility rate. 


\section{Case 2.1b: Sub-Cooled Liquid Water at the Valve Inlet}

As shown in Fig. 2.1b, the admission valve is the same device described for case 2.1a except that at the valve inlet the state of the fluid is sub-cooled liquid water at a pressure of 90 bars and a temperature of $230^{\circ} \mathrm{C}$ (these are the conditions applied to the actual fluid injectors utilized in the NPSEE analogue). Again, the valve is considered well insulated with negligible kinetic and potential effect.

As shown in Fig. 2.1b, and in the relative P-v diagram, the fluid state at the inlet is specified by a pressure $P_{1}=90$ bars and temperature $T_{1}=230^{\circ} \mathrm{C}$ for which the relative entropy value is $\mathrm{S}_{1}=2.608 \mathrm{~kJ} / \mathrm{kg}-\mathrm{K}$, and the specific enthalpy is $\mathrm{h}_{1}=997.535 \mathrm{~kJ} / \mathrm{kg}$. Similarly to case $2.1 \mathrm{a}$, the fluid state at the valve exit is fixed by applying the steady-state form of the energy rate balance equation, Eq. 2.1, and Eq. 2.2. Again, as for case 2.1a, the fluid state at the exit is fixed by knowledge of $P_{2}$ and $h_{2}$. Therefore, the value of the specific volume is $v_{2}=0.064 \mathrm{~m}^{3} / \mathrm{kg}$ and, by using Eq.2.9, the quality of the final state can be computed and used to determine the entropy at the valve exit.

$$
\mathrm{v}=\mathrm{v}_{\mathrm{f}}+\mathrm{X}\left(\mathrm{v}_{\mathrm{g}}-\mathrm{v}_{\mathrm{f}}\right)
$$

Overall, the value of the steam quality at the valve exit is $X_{2}=17 \%$ and the entropy $\mathrm{S}_{2}=2.701 \mathrm{~kJ} / \mathrm{kg}-\mathrm{K}$.

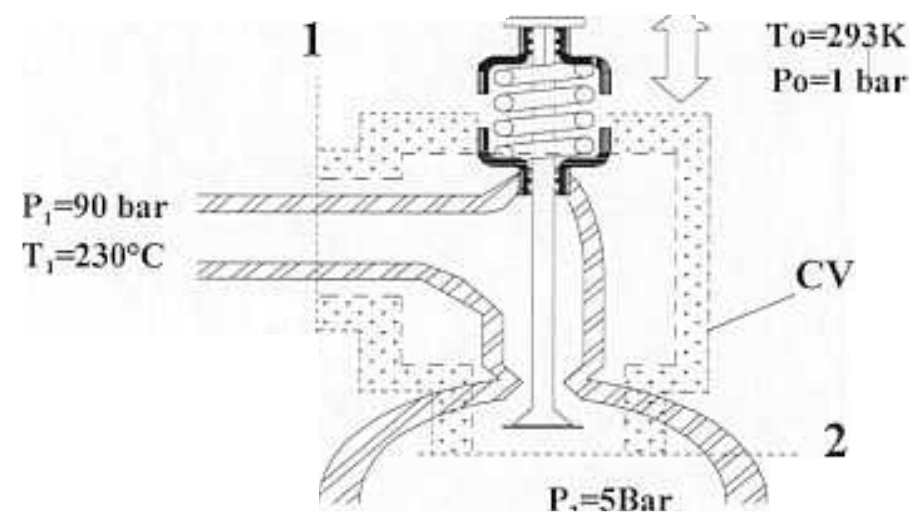

\section{1b: Throttling device with sub-cooled water at the inlet}

Figure

Therefore, by applying Eq.2.3 along with the assumptions of adiabatic conditions and no displacement of boundaries, the entropy production rates becomes:

$$
\frac{\sigma_{\text {Liq. }}}{\stackrel{r}{m}}=\mathrm{S}_{2}-\mathrm{S}_{1}=0.093 \mathrm{~kJ} / \mathrm{kg}-\mathrm{K}
$$

then, the irreversibility rate reduces to

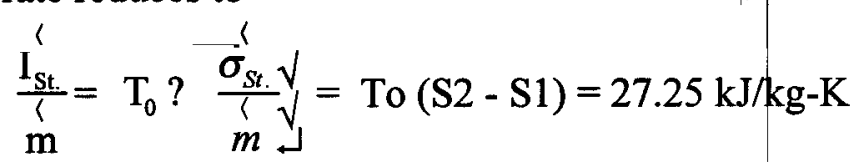

which is also equal to the value of the availability difference between the inlet and exit states. 
At this point, in order to estimate the impact of the irreversibilities caused by the valve in case $2.1 \mathrm{a}$, it is enough to set a typical value for an isentropic turbine efficiency of $63.2 \%$ (this is a reference value utilized in the actual NPSEE analogue) and perform the irreversibility rate estimate by using Eq. 2.4 applied at the inlet-exit of the turbine. The turbine inlet-exit conditions are shown in Fig. 2.2. Since the turbine is assumed to be well insulated, the irreversibility rate reduces to

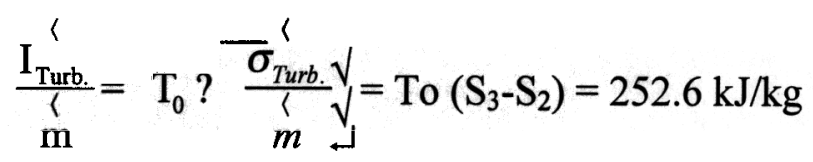

where the entropy at the inlet-exit conditions is $S_{2}=8.347 \mathrm{~kJ} / \mathrm{kg}-\mathrm{K}$, and $S_{3}=9.209 \mathrm{~kJ} / \mathrm{kg}-\mathrm{K}$ respectively.

To summarize, by comparing the irreversibility rate, and/or the flow availability destruction rate, generated in the valve at the conditions described in case $2.1 \mathrm{a}$, to the irreversibilities originated in the turbine alone, it is possible to notice that the ratio of the two irreversibility is about $73 \%$.

$$
\frac{\mathrm{I}_{\text {St. }}^{\prime}}{\mathrm{I}_{\text {Turb. }}^{\mathrm{r}}}=\frac{183.5}{252.6} \cdot ? 100 \cong 73 \%
$$

Therefore, by considering such a large value of availability destruction (or irreversibility production) due to the turbine admission valve alone, it is clear that there is room for improvement.

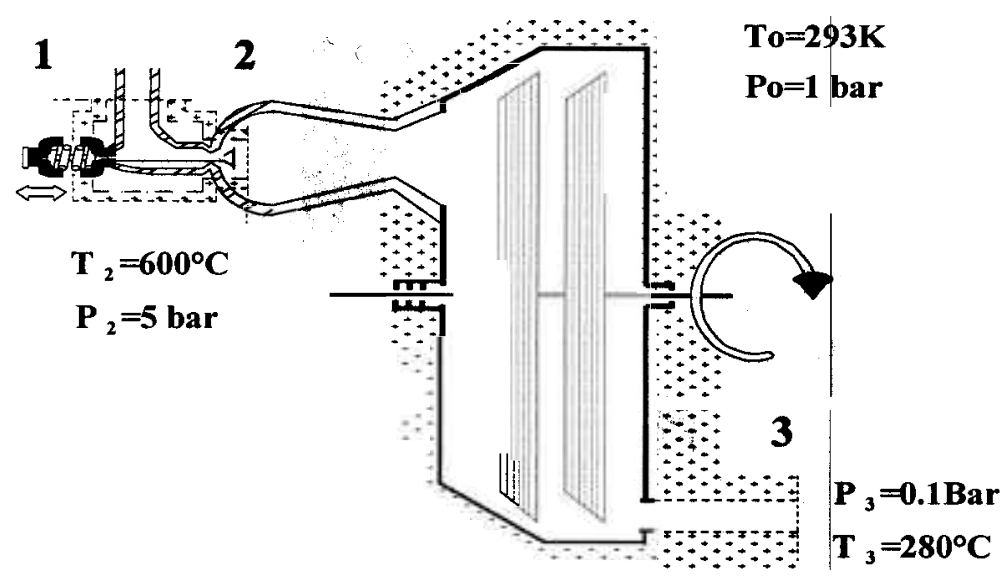

Figure 2.2: Turbine expansion

Overall, by considering the ratios of the flow availability destruction rates in the valve to that in the turbine, it is possible to conclude that by developing a special expander in which the heat addition occurs simultaneously with the fluid expansion, thereby avoiding the efficiency loss in the valve, it would automatically improve the efficiency. 